\title{
Monitoring Road Accidents and Injuries Using Variance Chart under Resampling and Having Indeterminacy
}

\author{
Muhammad Aslam * (i) and Mohammed Albassam (iD \\ Department of Statistics, Faculty of Science, King Abdulaziz University, Jeddah 21551, Saudi Arabia; \\ malbassam@kau.edu.sa \\ * Correspondence: aslam_ravian@hotmail.com
}

\begin{abstract}
The current manuscript proposes a $S_{N}^{2}-N E W M A$ control chart for monitoring road accidents and injuries using repetitive sampling. The proposed chart helps in identifying the shifts in accidents and injuries more quickly than existing charts. The application of the proposed chart will help in reducing and identifying the reasons for road accidents and road injuries efficiently.
\end{abstract}

Keywords: road injuries; road accident; monitoring; shift; variance

Citation: Aslam, M.; Albassam, M. Monitoring Road Accidents and Injuries Using Variance Chart under Resampling and Having Indeterminacy. Int. J. Environ. Res. Public Health 2021, 18, 5247. https:// doi.org/10.3390/ijerph18105247

Academic Editor: David Gil

Received: 9 March 2021

Accepted: 5 May 2021

Published: 14 May 2021

Publisher's Note: MDPI stays neutral with regard to jurisdictional claims in published maps and institutional affiliations.

Copyright: (c) 2021 by the authors. Licensee MDPI, Basel, Switzerland. This article is an open access article distributed under the terms and conditions of the Creative Commons Attribution (CC BY) license (https:/ / creativecommons.org/licenses/by/ $4.0 /)$.

\section{Introduction}

Control charts are designed to indicate a shift in the process and help industrialists, services companies, and the policy-makers department brings back the process to its normal state. Control charts have the ability to give prior information on when, on average, the process is going to be out-of-control. Therefore, control charts are wonderful tools to minimize the non-conforming items and increase the profit of industry and service companies. Control charts guide policy-makers in identifying the source of variations that cause the shift in the process from the center. References [1,2] discussed the applications of control charts.

Control charts have been broadly applied in monitoring road accidents, road injuries, and road crashes. Control charts lead highway experts in designing roads to minimize road accidents and injuries. In addition, these are helpful in identifying the factors that cause an increase in road accidents and injuries. The proper monitoring of roads with the help of control charts may significantly reduce road accidents and crashes. The application of control charts in monitoring children's road injuries was discussed by [3]. The various aspects of road accidents with the help of a control chart were discussed by [4]. References [5-8] presented the applications of control charts in monitoring road accidents. [1] introduced an exponentially weighted moving average (EWMA) for monitoring road accidents. A good statistical analysis of road accident data was discussed by [9,10]. Reference [11] presented the control charts for monitoring hazardous road accidents. Reference [12] presented the control charts using the Saudi traffic accidents data. $[13,14]$ presented the statistical analysis by using motorcyclist injuries data and road accident data. References $[15,16]$ presented excellent work in monitoring road accidents.

The neutrosophic logic, which is an extension of the fuzzy logic, is applied when indeterminacy is presented in the data [17]. According to [18], neutrosophic logic is more efficient than fuzzy logic and interval-based analysis. Reference [17] argued that neutrosophic statistics are more efficient than classical statistics in terms of the measurement of indeterminacy. Reference [19] proposed the neutrosophic EWMA (NEWMA) control chart for monitoring road accidents. Some other applications of neutrosophic statistics can be seen in [20-22]. Reference [23] worked on fuzzy-based non-parametric tests. Reference [24] proposed the median test using fuzzy logic. Reference [25] proposed the life-test using the fuzzy approach. Reference [26] proposed the idea of correlation using the fuzzy sets theory. Reference [27] proposed the signed-rank test for the interval data, and [28] presented the 
correlation analysis using the Pythagorean fuzzy approach. Reference [29] contributed excellent work in making control charts using functional data. Reference [30] studied the effects of indeterminacy on the performance of control charts.

Shewhart variance control charts are applied to monitor the variation in data. The EWMA variance control charts enhance the power of the Shewhart variance control charts, see [31]. References [19,32] introduced control charts under neutrosophic statistics. Reference [33] proposed a $S_{N}^{2}-N E W M A$ chart using a single sampling scheme. Repetitive sampling is the extension of single sampling and is applied when no decision is made on the basis of single sample information. In repetitive sampling, the process of selecting a sample is repeated when no decision is made on the first sample see [34]. To the best of our knowledge, there is still a gap in the design of variance NEWMA charts, $S_{N}^{2}-N E W M A$ being the control chart using repetitive sampling under neutrosophic statistics. In this paper, a $S_{N}^{2}-N E W M A$ control chart using repetitive sampling under neutrosophic statistics will be introduced and applied in monitoring road accidents and road injuries. It is expected that the proposed chart will be more efficient than the existing charts and better help indicate the shift in road accidents and road injuries compared to the existing charts.

\section{The Proposed $S_{N}^{2}-N E W M A$ Chart}

Let $X_{i N} \epsilon\left[X_{L}, X_{U}\right], i=1,2,3, \ldots, n_{N}$ be a neutrosophic random sample from the neutrosophic normal distribution with a neutrosophic mean of $\mu_{N} \in\left[\mu_{L}, \mu_{U}\right]$ and a neutrosophic variance of $\sigma_{N}^{2} \epsilon\left[\sigma_{L}^{2}, \sigma_{U}^{2}\right]$, where $n_{N} \epsilon\left[n_{L}, n_{U}\right]$ is a neutrosophic sample size. Suppose that $\bar{X}_{N} \epsilon\left[\bar{X}_{L}, \bar{X}_{U}\right]$ denotes the neutrosophic sample mean and $S_{N}^{2} \epsilon\left[S_{L}^{2}, S_{U}^{2}\right]$ presents the neutrosophic sample variance. Reference [33] proposed the following NEWMA statistic as a generalization of the EWMA statistic proposed by $[35,36]$.

$$
Z_{k N}=\left(1-\lambda_{N}\right) Z_{k-1, N}+\lambda_{N} T_{k N} ; Z_{k N} \epsilon\left[Z_{k L}, Z_{k U}\right], \lambda_{N} \epsilon\left[\lambda_{L}, \lambda_{U}\right]
$$

Note here that $E W M A_{N}=Z_{k N}=N E W M A$ and $\lambda_{N} \epsilon\left[\lambda_{L}, \lambda_{U}\right]$ are a neutrosophic smoothing constant, selected on the basis of personal experience, [37]. Industrial engineers are always uncertain on the selection of a suitable value for $\lambda_{N} \epsilon\left[\lambda_{L}, \lambda_{U}\right]$. Let $I_{N}$ denote the indeterminacy or uncertainty parameter. The neutrosophic form of $\lambda_{N} \epsilon\left[\lambda_{L}, \lambda_{U}\right]$ can be expressed as follows

$$
\lambda_{N}=\lambda_{L}+\lambda_{U} I_{\lambda N} ; I_{\lambda N} \epsilon\left[I_{\lambda N}, I_{\lambda N}\right]
$$

Note here that $\lambda_{L}$ denotes the values under classical statistics and is also known as the determined part of the neutrosophic form and $\lambda_{U} I_{\lambda N}$ denotes the indeterminate part of the neutrosophic form. Note here that the neutrosophic form reduces to a smoothing constant under classical statistics when no uncertainty is found in the selection of the smoothing constant.

The values of $T_{k N} \epsilon\left[T_{k L}, T_{k U}\right]$ in Equation (1) can be obtained as follows

$$
T_{k N}=a_{N}+b_{N} \cdot \ln \left(S_{k N}^{2}+c_{N}\right) ; a_{N} \epsilon\left[a_{L}, a_{U}\right], b_{N} \epsilon\left[b_{L}, b_{U}\right], c_{N} \epsilon\left[c_{L}, c_{U}\right]>[0,0]
$$

Reference [38] showed that $T_{k N} \epsilon\left[T_{k L}, T_{k U}\right]$ is closer to a neutrosophic normal distribution than $S_{N}^{2} \in\left[S_{L}^{2}, S_{U}^{2}\right]$. Reference [39] state: "the main expectation of this approach is that if $a_{N} \epsilon\left[a_{L}, a_{U}\right], b_{N} \epsilon\left[b_{L}, b_{U}\right]$ and $c_{N} \epsilon\left[c_{L}, c_{U}\right]$ are judiciously selected, then this transformation may result in approximate normality to $T_{k N} \epsilon\left[T_{k L}, T_{k U}\right]^{\prime \prime}$. The neutrosophic control limits (NCLs) under repetitive sampling with starting values of $Z_{0 N}=0$ are given by:

$$
\begin{gathered}
L C L_{1 N}=E\left(T_{k N}\right)-k_{1 N} \sqrt{\frac{\lambda_{N}}{2-\lambda_{N}}} \sigma\left(T_{k N}\right) ; L C L_{1 N} \epsilon\left[L C L_{1 L}, L C L_{1 U}\right] \\
U C L_{1 N}=E\left(T_{k N}\right)+k_{1 N} \sqrt{\frac{\lambda_{N}}{2-\lambda_{N}}} \sigma\left(T_{k N}\right) ; U C L_{1 N} \epsilon\left[U C L_{1 L}, U C L_{1 U}\right]
\end{gathered}
$$




$$
\begin{gathered}
L C L_{2 N}=E\left(T_{k N}\right)-k_{2 N} \sqrt{\frac{\lambda_{N}}{2-\lambda_{N}}} \sigma\left(T_{k N}\right) ; L C L_{2 N} \epsilon\left[L C L_{2 L}, L C L_{2 U}\right] \\
U C L_{2 N}=E\left(T_{k N}\right)+k_{2 N} \sqrt{\frac{\lambda_{N}}{2-\lambda_{N}}} \sigma\left(T_{k N}\right) ; U C L_{2 N} \epsilon\left[U C L_{2 L}, U C L_{2 U}\right]
\end{gathered}
$$

Note that $k_{1 N} \epsilon\left[k_{1 L}, k_{1 U}\right]$ and $k_{2 N} \epsilon\left[k_{2 L}, k_{2 U}\right]$ present a neutrosophic control limit coefficient associated with NCLs.

The NCLs given in Equations (1)-(4) are approximate but widely applied due to simplicity, see [39]. The exact NCLs for $S_{N}^{2}-N E W M A$ under repetitive sampling are given as:

$$
\begin{gathered}
L C L_{1 N}=E\left(T_{k N}\right)-k_{1 N} \sqrt{\frac{\lambda_{N}\left\{1-\left(1-\lambda_{N}\right)^{2 k}\right\}}{2-\lambda_{N}}} \sigma\left(T_{k N}\right) ; L C L_{N} \epsilon\left[L C L_{L}, L C L_{U}\right] \\
U C L_{1 N}=E\left(T_{k N}\right)+k_{1 N} \sqrt{\frac{\lambda_{N}\left\{1-\left(1-\lambda_{N}\right)^{2 k}\right\}}{2-\lambda_{N}}} \sigma\left(T_{k N}\right) ; U C L_{N} \epsilon\left[U C L_{L}, U C L_{U}\right] \\
L C L_{2 N}=E\left(T_{k N}\right)-k_{2 N} \sqrt{\frac{\lambda_{N}\left\{1-\left(1-\lambda_{N}\right)^{2 k}\right\}}{2-\lambda_{N}}} \sigma\left(T_{k N}\right) ; L C L_{N} \epsilon\left[L C L_{L}, L C L_{U}\right] \\
U C L_{2 N}=E\left(T_{k N}\right)+k_{2 N} \sqrt{\frac{\lambda_{N}\left\{1-\left(1-\lambda_{N}\right)^{2 k}\right\}}{2-\lambda_{N}}} \sigma\left(T_{k N}\right) ; U C L_{N} \epsilon\left[U C L_{L}, U C L_{U}\right]
\end{gathered}
$$

By following [39], the approximate control limits are considered in this paper.

\section{The Proposed Control Chart}

As mentioned in [39], the transformation $T_{k N}=\ln S_{N}^{2}$ makes the limits that are not symmetrical in a traditional $S^{2}$ control chart symmetrical. The proposed $S_{N}^{2}-N E W M A$ will be operated as follows:

Step-1: Compute statistic $Z_{k N} \in\left[Z_{k L}, Z_{k U}\right]$ for $n_{N} \in\left[n_{L}, n_{U}\right]$ sample size when indeterminacy parameter $I_{N}$ is specified.

Step-2: If $Z_{k N} \epsilon\left[Z_{k L}, Z_{k U}\right] \geq U C L_{2 U}$ or $Z_{k N} \epsilon\left[Z_{k L}, Z_{k U}\right] \leq L C L_{2 U}$, the process is said to be out-of-control. The process is said to be in-control if $L C L_{1 U} \leq Z_{k N} \leq U C L_{1 U}$, otherwise repeat step 1 .

The proposed control chart has four control limits. The proposed control chart reduces to the control chart proposed by [33] when no repetition is needed. The probability of being in-control for the proposed control chart is:

$$
P_{o u t, N}^{0}=\frac{P_{o u t, 1 N}^{0}}{1-P_{r e p, N}^{0}}
$$

where $P_{r e p, N}^{0}$ is the probability of repetition and $P_{o u t, 1 N}^{0}$ is the probability of being in-control for the single sampling, given by:

$$
P_{\text {out }, 1 N}^{0}=P\left(L C L_{1 U} \leq Z_{k N} \leq U C L_{1 U} / S_{N 0}^{2}\right) ; S_{N 0}^{2} \epsilon\left[S_{L 0}^{2}, S_{U 0}^{2}\right]
$$

The probability of being in-control for the shifted process is given by

$$
P_{o u t, N}^{1}=\frac{P_{o u t, 1 N}^{1}}{1-P_{r e p, N}^{1}}
$$


where $P_{r e p, N}^{1}$ is the probability of repetition and $P_{o u t, 1 N}^{1}$ is the probability of in-control for the single sampling, given by:

$$
P_{\text {out }, 1 N}^{1}=P\left(L C L_{1 U} \leq Z_{k N} \leq U C L_{1 U} / S_{N 1}^{2}\right) ; S_{N 1}^{2} \epsilon\left[S_{L 1}^{2}, S_{U 1}^{2}\right]
$$

The neutrosophic average run length (NARL) for the in-control and shifted process are given by

$$
\begin{aligned}
& A R L_{0 N}=\frac{1}{1-P\left(L C L_{N} \leq Z_{k N} \leq U C L_{N} / S_{N 0}^{2}\right)} ; A R L_{0 N} \epsilon\left[A R L_{0 L}, A R L_{0 U}\right] \\
& A R L_{1 N}=\frac{1}{1-P\left(L C L_{N} \leq Z_{k N} \leq U C L_{N} / S_{N 1}^{2}\right)} ; A R L_{1 N} \epsilon\left[A R L_{1 L}, A R L_{1 U}\right]
\end{aligned}
$$

The following is the neutrosophic Monte Carlo (NMS) used to find the values of $k_{1 N} \epsilon\left[k_{1 L}, k_{1 U}\right], k_{2 N} \epsilon\left[k_{2 L}, k_{2 U}\right]$ and $A R L_{1 N} \epsilon\left[A R L_{1 L}, A R L_{1 U}\right]$, when $A R L_{0 N} \epsilon\left[A R L_{0 L}, A R L_{0 U}\right]$ is fixed.

1. Fix the sample size $n_{N} \epsilon\left[n_{L}, n_{U}\right]$ and generate 10,000 random samples of size $n_{N} \epsilon\left[n_{L}, n_{U}\right]$ and select the values of $a_{N} \epsilon\left[a_{L}, a_{U}\right], b_{N} \epsilon\left[b_{L}, b_{U}\right]$ and $c_{N} \epsilon\left[c_{L}, c_{U}\right]$ from [33]. Compute the values of the statistic $Z_{k N} \in\left[Z_{k L}, Z_{k U}\right]$ for the specified indeterminacy parameter $I_{N}$ and plot these values of NCLs.

2. Note the first out-of-control values for the 10,000 random samples and compute $A R L_{0 N} \epsilon\left[A R L_{0 L}, A R L_{0 U}\right]$ and neutrosophic standard division (NSD) and select the values of $k_{1 N} \epsilon\left[k_{1 L}, k_{1 U}\right]$ and $k_{2 N} \epsilon\left[k_{2 L}, k_{2 U}\right]$ for which $A R L_{0 N} \epsilon\left[A R L_{0 L}, A R L_{0 U}\right]$ is very close to the specified values of $A R L_{0 N} \epsilon\left[A R L_{0 L}, A R L_{0 U}\right]$.

3. Using the selected values of $k_{1 N} \epsilon\left[k_{1 L}, k_{1 U}\right]$ and $k_{2 N} \epsilon\left[k_{2 L}, k_{2 U}\right]$, compute $Z_{k N} \epsilon\left[Z_{k L}, Z_{k U}\right]$ for the data generated at various values of shift $c$. Compute the values of $A R L_{1 N} \epsilon\left[A R L_{1 L}, A R L_{1 U}\right]$ and NSD for various values of $c$.

Using the above algorithm, the values of $A R L_{1 N} \epsilon\left[A R L_{1 L}, A R L_{1 U}\right]$ and NSD for various values of $c, A R L_{0 N} \epsilon\left[A R L_{0 L}, A R L_{0 U}\right], n_{N} \epsilon\left[n_{L}, n_{U}\right]$ and $I_{N}$ are placed in Tables 1-6. Table 1 is presented for $n_{N} \epsilon[3,5]$ and $\lambda_{N}=0.08+0.12 I_{\lambda_{N}} ; I_{\lambda_{N}} \epsilon[0,0.3]$. Table 2 is given for $n_{N} \epsilon[3,5]$ and $\lambda_{N}=0.18+0.22 I_{\lambda_{N}} ; I_{\lambda N} \epsilon[0,0.18]$. Table 3 is given for $n_{N} \epsilon[3,5]$ and $\lambda_{N}=0.28+0.32 I_{\lambda N} ; I_{\lambda N} \epsilon[0,0.13]$. Table 4 is presented for $n_{N} \epsilon[8,10]$ and $\lambda_{N}=0.08+$ $0.12 I_{N} ; I_{N} \epsilon[0,0.3]$. Table 5 is given for $n_{N} \epsilon[8,10]$ and $\lambda_{N}=0.18+0.22 I_{\lambda N} ; I_{\lambda N} \epsilon[0,0.18]$. Finally, Table 6 is given for $n_{N} \epsilon[8,10]$ and $\lambda_{N}=0.28+0.32 I_{\lambda N} ; I_{\lambda N} \epsilon[0,0.13]$. The R codes

\begin{tabular}{|c|c|c|c|c|}
\hline \multirow[t]{2}{*}{$c$} & \multicolumn{2}{|c|}{$\begin{array}{c}\mathrm{k}_{1}=[2.60,2.807], \mathrm{k}_{2}=[1.65,1.622] \\
\mathrm{ARL}_{0 \mathrm{~N}}=[300,300]\end{array}$} & \multicolumn{2}{|c|}{$\begin{array}{c}\mathbf{k}_{1}=[2.746,2.875], \mathrm{k}_{2}=[1.741,1.612] \\
\mathrm{ARL}_{0 \mathrm{~N}}=[370,370]\end{array}$} \\
\hline & NARL & NSD & NARL & NSD \\
\hline 1.00 & {$[306.67,300.58]$} & {$[311.79,294.36]$} & {$[370.27,370.12]$} & {$[398.78,362.83]$} \\
\hline 1.05 & {$[131.79,116.61]$} & {$[139.41,124.24]$} & {$[158.75,135.45]$} & {$[168.84,142.24]$} \\
\hline 1.1 & {$[63.80,44.18]$} & {$[70.27,46.39]$} & {$[77.63,51.89]$} & {$[89.02,52.37]$} \\
\hline 1.15 & {$[33.24,22.42]$} & {$[37.08,22.88]$} & {$[36.97,24.85]$} & {$[40.83,24.06]$} \\
\hline 1.2 & {$[21.35,13.50]$} & {$[23.31,13.65]$} & {$[22.66,12.96]$} & {$[25.26,12.71]$} \\
\hline 1.25 & {$[14.13,8.51]$} & {$[15.65,8.30]$} & {$[15.05,9.36]$} & {$[17.21,8.72]$} \\
\hline 1.3 & {$[9.43,6.45]$} & {$[10.03,5.75]$} & {$[10.88,6.06]$} & {$[12.18,5.59]$} \\
\hline 1.4 & {$[5.97,4.01]$} & {$[6.17,3.31]$} & {$[6.75,4.07]$} & {$[6.94,3.47]$} \\
\hline 1.5 & {$[4.28,2.99]$} & {$[4.46,2.40]$} & {$[4.46,2.99]$} & {$[4.20,2.29]$} \\
\hline 1.6 & {$[3.23,2.31]$} & {$[3.21,1.56]$} & {$[3.66,2.36]$} & {$[3.20,1.60]$} \\
\hline 1.7 & {$[2.69,2.07]$} & {$[2.35,1.34]$} & {$[2.91,2.05]$} & {$[2.42,1.28]$} \\
\hline 1.8 & {$[2.23,1.75]$} & {$[1.87,1.02]$} & {$[2.56,1.75]$} & {$[2.15,1.05]$} \\
\hline 1.9 & {$[2.02,1.61]$} & {$[1.64,0.94]$} & {$[2.21,1.63]$} & {$[1.82,0.92]$} \\
\hline
\end{tabular}
to make the Tables are given in Appendix A.

Table 1. The NARL when $n_{N} \epsilon[3,5]$ and $I_{\lambda U}=0.3$. 
Table 1. Cont.

\begin{tabular}{|c|c|c|c|c|}
\hline \multirow{2}{*}{$c$} & \multicolumn{2}{|c|}{$\begin{array}{c}\mathrm{k}_{1}=[2.60,2.807], \mathrm{k}_{2}=[1.65,1.622] \\
\mathrm{ARL}_{0 \mathrm{~N}}=[300,300]\end{array}$} & \multicolumn{2}{|c|}{$\begin{array}{c}\mathrm{k}_{1}=[2.746,2.875], \mathrm{k}_{2}=[1.741,1.612] \\
\mathrm{ARL}_{0 \mathrm{~N}}=[370,370]\end{array}$} \\
\hline & NARL & NSD & NARL & NSD \\
\hline 2.0 & {$[1.96,1.49]$} & {$[1.56,0.76]$} & {$[1.88,1.54]$} & {$[1.34,0.81]$} \\
\hline 2.25 & {$[1.55,1.31]$} & {$[0.98,0.61]$} & {$[1.67,1.33]$} & {$[1.06,0.60]$} \\
\hline 2.5 & {$[1.46,1.20]$} & {$[0.84,0.46]$} & {$[1.54,1.22]$} & {$[1.03,0.49]$} \\
\hline 3.0 & {$[1.27,1.10]$} & {$[0.58,0.33]$} & {$[1.30,1.13]$} & {$[0.67,0.38]$} \\
\hline 4.0 & {$[1.13,1.03]$} & {$[0.40,0.19]$} & {$[1.15,1.03]$} & {$[0.43,0.18]$} \\
\hline
\end{tabular}

Table 2. The NARL when $n_{N} \epsilon[3,5]$ and $I_{\lambda U}=0.18$.

\begin{tabular}{|c|c|c|c|c|}
\hline \multirow[t]{2}{*}{$c$} & \multicolumn{2}{|c|}{$\begin{array}{c}\mathrm{k}_{1}=[2.746,2.887], \mathrm{k}_{2}=[1.741,1.612] \\
\mathrm{ARL}_{0 \mathrm{~N}}=[300,300]\end{array}$} & \multicolumn{2}{|c|}{$\begin{array}{c}\mathbf{k}_{1}=[2.824,2.949], \mathbf{k}_{2}=[1.782,1.726] \\
\operatorname{ARL}_{0 \mathrm{~N}}=[370,370]\end{array}$} \\
\hline & NARL & NSD & NARL & NSD \\
\hline 1.00 & {$[302.77,299.08]$} & {$[322.28,279.96]$} & {$[371.30,370.76]$} & {$[380.06,342.35]$} \\
\hline 1.05 & {$[140.91,126.91]$} & [149.12,131.00] & {$[170.67,144.53]$} & {$[176.01,148.56]$} \\
\hline 1.1 & {$[76.46,51.85]$} & {$[77.38,51.80]$} & {$[89.82,63.61]$} & {$[90.73,62.82]$} \\
\hline 1.15 & {$[46.43,27.69]$} & {$[47.98,26.04]$} & {$[47.37,29.93]$} & {$[50.06,28.22]$} \\
\hline 1.2 & {$[27.10,17.24]$} & {$[28.23,16.96]$} & {$[31.76,17.83]$} & {$[32.01,17.18]$} \\
\hline 1.25 & {$[19.05,10.37]$} & {$[19.25,10.35]$} & {$[20.88,11.00]$} & {$[21.02,10.08]$} \\
\hline 1.3 & {$[13.37,7.00]$} & {$[12.30,6.07]$} & {$[13.72,8.27]$} & {$[14.65,7.51]$} \\
\hline 1.4 & {$[8.43,4.58]$} & {$[8.15,3.84]$} & {$[8.95,4.87]$} & {$[7.94,4.07]$} \\
\hline 1.5 & {$[5.83,3.29]$} & {$[5.28,2.60]$} & {$[5.97,3.37]$} & {$[5.49,2.55]$} \\
\hline 1.6 & {$[4.46,2.53]$} & {$[4.00,1.84]$} & {$[4.97,2.74]$} & {$[4.26,1.82]$} \\
\hline 1.7 & {$[3.60,2.17]$} & {$[3.03,1.40]$} & {$[3.78,2.26]$} & {$[3.16,1.49]$} \\
\hline 1.8 & {$[3.22,1.90]$} & {$[2.74,1.24]$} & {$[3.24,2.03]$} & {$[2.52,1.30]$} \\
\hline 1.9 & {$[2.63,1.76$} & {$[2.02,1.08]$} & {$[2.79,1.78]$} & {$[2.10,1.06]$} \\
\hline 2.0 & {$[2.49,1.53]$} & {$[1.91,0.83]$} & {$[2.65,1.65]$} & {$[1.91,0.91]$} \\
\hline 2.25 & {$[2.06,1.33]$} & {$[1.36,0.59]$} & {$[2.06,1.38]$} & {$[1.37,0.64]$} \\
\hline 2.5 & {$[1.75,1.21]$} & {$[1.07,0.50]$} & {$[1.76,1.25]$} & {$[1.09,0.54]$} \\
\hline 3.0 & {$[1.39,1.13]$} & {$[0.70,0.38]$} & {$[1.49,1.11]$} & {$[0.86,0.33]$} \\
\hline 4.0 & {$[1.23,1.04]$} & {$[0.52,0.22]$} & {$[1.21,1.04]$} & {$[0.49,0.21]$} \\
\hline
\end{tabular}

Table 3. The NARL when $n_{N} \epsilon[3,5]$ and $I_{\lambda U}=0.13$.

\begin{tabular}{|c|c|c|c|c|}
\hline \multirow[t]{2}{*}{$c$} & \multicolumn{2}{|c|}{$\begin{array}{c}k_{1}=[2.823,2.888], k_{2}=[1.782,1.687] \\
\operatorname{ARL}_{0 N}=[300,300]\end{array}$} & \multicolumn{2}{|c|}{$\begin{array}{c}\mathbf{k}_{1}=[2.907,2.958], \mathbf{k}_{2}=[1.752,1.617] \\
\mathrm{ARL}_{0 \mathrm{~N}}=[370,370]\end{array}$} \\
\hline & NARL & NSD & NARL & NSD \\
\hline 1.00 & {$[299.03,300.32]$} & {$[311.97,281.24]$} & {$[369.70,370.73]$} & {$[374.55,352.17]$} \\
\hline 1.05 & {$[142.14,129.44]$} & {$[143.09,127.88]$} & {$[164.25,135.02]$} & {$[165.41,132.88]$} \\
\hline 1.1 & {$[78.27,54.44]$} & {$[75.26,55.67]$} & {$[93.17,65.74]$} & {$[93.99,65.19]$} \\
\hline 1.15 & {$[47.16,31.04]$} & {$[46.35,29.41]$} & {$[52.44,31.17]$} & {$[54.35,29.80]$} \\
\hline 1.2 & {$[31.19,19.61]$} & {$[31.68,18.60]$} & {$[33.70,19.81]$} & {$[33.91,19.41]$} \\
\hline 1.25 & {$[20.81,12.15]$} & {$[20.72,12.08]$} & {$[22.70,12.02]$} & {$[22.56,11.24]$} \\
\hline 1.3 & {$[15.35,8.17]$} & {$[15.29,7.30]$} & {$[16.04,8.86]$} & {$[15.96,7.97]$} \\
\hline 1.4 & {$[8.89,5.09]$} & {$[8.02,4.38]$} & {$[9.77,5.03]$} & {$[9.41,4.04]$} \\
\hline 1.5 & {$[6.44,3.61]$} & {$[5.99,2.94]$} & {$[6.66,3.56]$} & {$[5.89,2.69]$} \\
\hline 1.6 & {$[5.02,2.75]$} & {$[4.38,2.03]$} & {$[5.01,2.60]$} & {$[4.47,1.85]$} \\
\hline 1.7 & {$[3.80,2.26]$} & {$[3.19,1.51]$} & {$[4.07,2.17]$} & {$[3.24,1.45]$} \\
\hline 1.8 & {$[3.25,2.00]$} & {$[2.76,1.31]$} & {$[3.35,1.92]$} & {$[2.61,1.31]$} \\
\hline 1.9 & {$[2.91,1.77]$} & {$[2.27,1.13]$} & {$[2.90,1.67]$} & {$[2.27,0.92]$} \\
\hline 2.0 & {$[2.53,1.59]$} & {$[1.92,0.89]$} & {$[2.47,1.61]$} & {$[1.92,0.89]$} \\
\hline 2.25 & {$[2.06,1.36]$} & {$[1.43,0.63]$} & {$[2.04,1.34]$} & {$[1.40,0.65]$} \\
\hline 2.5 & {$[1.76,1.23]$} & {$[1.11,0.51]$} & {$[1.73,1.24]$} & {$[1.10,0.51]$} \\
\hline 3.0 & {$[1.48,1.13]$} & {$[0.87,0.36]$} & {$[1.48,1.09]$} & {$[0.84,0.32]$} \\
\hline 4.0 & {$[1.23,1.05]$} & {$[0.53,0.23]$} & {$[1.25,1.04]$} & {$[0.57,0.21]$} \\
\hline
\end{tabular}


Table 4. The NARL when $n_{N} \epsilon[8,10]$ and $I_{\lambda U}=0.3$.

\begin{tabular}{|c|c|c|c|c|}
\hline \multirow{2}{*}{$c$} & \multicolumn{2}{|c|}{$\begin{array}{c}k_{1}=[2.756,2.899], k_{2}=[1.467,1.452] \\
\operatorname{ARL}_{0 N}=[300,300]\end{array}$} & \multicolumn{2}{|c|}{$\begin{array}{c}\mathrm{k}_{1}=[2.849,2.968], \mathrm{k}_{2}=[1.567,1.452] \\
\mathrm{ARL}_{0 \mathrm{~N}}=[370,370]\end{array}$} \\
\hline & NARL & NSD & NARL & NSD \\
\hline 1.00 & {$[301.25,300.24]$} & {$[289.01,302.93]$} & {$[369.02,371.91]$} & {$[355.43,378.85]$} \\
\hline 1.05 & {$[88.50,86.94]$} & {$[84.53,84.26]$} & {$[100.77,92.29]$} & {$[102.60,91.54]$} \\
\hline 1.1 & {$[25.72,23.21]$} & {$[25.30,22.29]$} & {$[27.70,24.97]$} & {$[27.70,24.51]$} \\
\hline 1.15 & {$[11.03,9.93]$} & {$[11.08,9.08]$} & {$[12.00,10.25]$} & {$[11.50,9.08]$} \\
\hline 1.2 & {$[6.33,5.66]$} & {$[5.78,4.73]$} & {$[6.86,5.61]$} & {$[5.81,4.30]$} \\
\hline 1.25 & {$[4.28,3.99]$} & {$[3.43,3.01]$} & {$[4.77,3.90]$} & {$[3.94,2.86]$} \\
\hline 1.3 & {$[3.46,3.06]$} & {$[2.61,2.17]$} & {$[3.78,2.97]$} & {$[2.78,2.09]$} \\
\hline 1.4 & {$[2.45,2.12]$} & {$[1.71,1.24]$} & {$[2.49,2.10]$} & {$[1.66,1.31]$} \\
\hline 1.5 & {$[1.90,1.79]$} & {$[1.18,1.00]$} & {$[2.00,1.70]$} & {$[1.23,0.89]$} \\
\hline 1.6 & {$[1.67,1.49]$} & {$[0.98,0.75]$} & {$[1.71,1.48]$} & {$[0.92,0.72]$} \\
\hline 1.7 & {$[1.44,1.33]$} & {$[0.69,0.57]$} & {$[1.51,1.35]$} & {$[0.79,0.62]$} \\
\hline 1.8 & {$[1.32,1.25]$} & {$[0.59,0.50]$} & {$[1.39,1.26]$} & {$[0.65,0.54]$} \\
\hline 1.9 & {$[1.26,1.17]$} & {$[0.54,0.44]$} & {$[1.33,1.17]$} & {$[0.58,0.42]$} \\
\hline 2.0 & {$[1.23,1.13]$} & {$[0.49,0.35]$} & {$[1.20,1.12]$} & {$[0.45,0.35]$} \\
\hline 2.25 & {$[1.08,1.07]$} & {$[0.29,0.27]$} & {$[1.13,1.07]$} & {$[0.37,0.27]$} \\
\hline 2.5 & {$[1.06,1.03]$} & {$[0.24,0.18]$} & {$[1.07,1.03]$} & {$[0.27,0.20]$} \\
\hline 3.0 & {$[1.01,1.01]$} & {$[0.11,0.11]$} & {$[1.02,1.01]$} & {$[0.15,0.09]$} \\
\hline 4.0 & {$[1.00,1.00]$} & {$[0.05,0.03]$} & {$[1.00,1.00]$} & {$[0.07,0.00]$} \\
\hline
\end{tabular}

Table 5. The NARL when $n_{N} \epsilon[8,10]$ and $I_{\lambda U}=0.18$.

\begin{tabular}{|c|c|c|c|c|}
\hline \multirow{2}{*}{$c$} & \multicolumn{2}{|c|}{$\begin{array}{c}\mathrm{k}_{1}=[2.929,2.995], \mathrm{k}_{2}=[1.637,1.442] \\
\mathrm{ARL}_{0 \mathrm{~N}}=[300,300]\end{array}$} & \multicolumn{2}{|c|}{$\begin{array}{c}\mathrm{k}_{1}=[2.989,3.043], \mathrm{k}_{2}=[1.687,1.652] \\
\mathrm{ARL}_{0 \mathrm{~N}}=[370,370]\end{array}$} \\
\hline & NARL & NSD & NARL & NSD \\
\hline 1.00 & {$[300.61,301.96]$} & {$[289.96,307.92]$} & {$[369.57,371.06]$} & {$[361.81,374.03]$} \\
\hline 1.05 & {$[103.60,101.21]$} & {$[106.57,99.75]$} & {$[124.33,121.34]$} & {$[120.92,115.25]$} \\
\hline 1.1 & {$[38.85,30.55]$} & {$[37.33,28.94]$} & {$[41.19,36.64]$} & {$[40.42,36.47]$} \\
\hline 1.15 & {$[15.86,12.48]$} & {$[14.32,11.60]$} & {$[17.62,14.74]$} & {$[16.45,13.06]$} \\
\hline 1.2 & {$[9.16,6.92]$} & {$[7.57,5.66]$} & {$[9.85,7.74]$} & {$[8.71,6.23]$} \\
\hline 1.25 & {$[5.99,4.51]$} & {$[4.85,3.68]$} & {$[6.16,4.85]$} & {$[4.84,3.82]$} \\
\hline 1.3 & {$[4.21,3.20]$} & {$[3.17,2.49]$} & {$[4.61,3.72]$} & {$[3.61,2.68]$} \\
\hline 1.4 & {$[2.93,2.08]$} & {$[2.05,1.37]$} & {$[3.07,2.57]$} & {$[2.13,1.69]$} \\
\hline 1.5 & {$[2.21,1.76]$} & {$[1.33,1.01]$} & {$[2.34,1.83]$} & {$[1.52,0.98]$} \\
\hline 1.6 & {$[1.84,1.45]$} & {$[1.02,0.69]$} & {$[1.86,1.65]$} & {$[1.04,0.84]$} \\
\hline 1.7 & {$[1.57,1.32]$} & {$[0.82,0.61]$} & {$[1.64,1.39]$} & {$[0.88,0.64]$} \\
\hline 1.8 & {$[1.47,1.20]$} & {$[0.73,0.46]$} & {$[1.50,1.29]$} & {$[0.74,0.53]$} \\
\hline 1.9 & {$[1.34,1.18]$} & {$[0.57,0.44]$} & {$[1.37,1.21]$} & {$[0.60,0.43]$} \\
\hline 2.0 & {$[1.26,1.11]$} & {$[0.53,0.33]$} & {$[1.29,1.15]$} & {$[0.55,0.39]$} \\
\hline 2.25 & {$[1.16,1.04]$} & {$[0.38,0.22]$} & {$[1.16,1.09]$} & {$[0.39,0.30]$} \\
\hline 2.5 & {$[1.07,1.03]$} & {$[0.29,0.17]$} & {$[1.06,1.03]$} & {$[0.25,0.17]$} \\
\hline 3.0 & {$[1.03,1.00]$} & {$[0.17,0.08]$} & {$[1.03,1.00]$} & {$[0.18,0.07]$} \\
\hline 4.0 & {$[1.00,1.00]$} & {$[0.07,0.03]$} & {$[1.00,1.00]$} & {$[0.060 .00]$} \\
\hline
\end{tabular}

From Tables 1-6, the following trends can be observed.

1. For other same parameters, the values of $A R L_{1 N} \epsilon\left[A R L_{1 L}, A R L_{1 U}\right]$ and NSD increase as the values of $I_{\lambda U}$ decrease.

2. For the other same parameters, $A R L_{1 N} \epsilon\left[A R L_{1 L}, A R L_{1 U}\right]$ and NSD decrease as the values of $n_{N} \epsilon\left[n_{L}, n_{U}\right]$ increase.

3. The values of $A R L_{1 N} \in\left[A R L_{1 L}, A R L_{1 U}\right]$ and NSD decrease as the value of the parameter $c$ increases from 1.00 to 4.0 .

4. For the same value of $c$, the values of $A R L_{1 N} \in\left[A R L_{1 L}, A R L_{1 U}\right]$ and NSD increase as the value of $A R L_{0 N}$ increases. 
Table 6. The NARL when $n_{N} \epsilon[8,10]$ and $I_{\lambda U}=0.13$.

\begin{tabular}{|c|c|c|c|c|}
\hline \multirow[t]{2}{*}{$c$} & \multicolumn{2}{|c|}{$\begin{array}{c}\mathrm{k}_{1}=[2.977,2.990], \mathrm{k}_{2}=[1.653,1.584] \\
\mathrm{ARL}_{0 \mathrm{~N}}=[300,300]\end{array}$} & \multicolumn{2}{|c|}{$\begin{array}{c}\mathbf{k}_{1}=[3.037,3.056], \mathbf{k}_{2}=[1.852,1.652] \\
\operatorname{ARL}_{0 N}=[370,370]\end{array}$} \\
\hline & NARL & NSD & NARL & NSD \\
\hline 1.00 & {$[301.83,300.77]$} & {$[301.34,298.27]$} & {$[370.70,370.45]$} & {$[366.03,361.76]$} \\
\hline 1.05 & {$[111.33,105.96]$} & {$[114.26,105.79]$} & {$[142.94,138.04]$} & {$[148.14,132.91]$} \\
\hline 1.1 & {$[46.33,37.46]$} & {$[42.97,36.86]$} & {$[50.18,42.23]$} & {$[49.57,40.51]$} \\
\hline 1.15 & {$[19.84,15.37]$} & {$[17.77,14.55]$} & {$[24.12,16.80]$} & {$[22.87,16.02]$} \\
\hline 1.2 & {$[11.10,8.30]$} & {$[10.16,7.23]$} & {$[12.17,9.60]$} & {$[10.83,8.91]$} \\
\hline 1.25 & {$[6.64,5.35]$} & {$[5.46,4.33]$} & {$[8.01,5.50]$} & {$[7.08,4.49]$} \\
\hline 1.3 & {$[4.79,3.87]$} & {$[3.87,2.94]$} & {$[5.54,3.99]$} & {$[4.21,2.96]$} \\
\hline 1.4 & {$[3.00,2.45]$} & {$[2.15,1.65]$} & {$[3.44,2.58]$} & {$[2.40,1.74]$} \\
\hline 1.5 & {$[2.26,1.80]$} & {$[1.49,0.98]$} & {$[2.43,1.87]$} & {$[1.47,1.07]$} \\
\hline 1.6 & {$[1.79,1.54]$} & {$[1.02,0.83]$} & {$[2.05,1.59]$} & {$[1.24,0.82]$} \\
\hline 1.7 & {$[1.57,1.35]$} & {$[0.84,0.61]$} & {$[1.71,1.42]$} & {$[0.91,0.70]$} \\
\hline 1.8 & {$[1.43,1.22]$} & {$[0.74,0.49]$} & {$[1.53,1.26]$} & {$[0.78,0.53]$} \\
\hline 1.9 & {$[1.33,1.15]$} & {$[0.58,0.40]$} & {$[1.37,1.19]$} & {$[0.62,0.44]$} \\
\hline 2.0 & {$[1.21,1.12]$} & {$[0.47,0.36]$} & {$[1.32,1.12]$} & {$[0.58,0.35]$} \\
\hline 2.25 & {$[1.13,1.05]$} & {$[0.38,0.23]$} & {$[1.15,1.06]$} & {$[0.38,0.24]$} \\
\hline 2.5 & {$[1.07,1.03]$} & {$[0.29,0.17]$} & {$[1.09,1.02]$} & {$[0.30,0.14]$} \\
\hline 3.0 & {$[1.02,1.00]$} & {$[0.16,0.08]$} & {$[1.03,1.00]$} & {$[0.19,0.08]$} \\
\hline 4.0 & {$[1.00,1.00]$} & {$[0.07,0.00]$} & [1.011.00] & {$[0.11,0.00]$} \\
\hline
\end{tabular}

\section{Comparative Study}

In this section, the advantage of the proposed control chart is discussed in terms of NARLs and NSD. The proposed chart is compared to two existing control charts proposed by [39] under classical statistics and [33] under neutrosophic statistics. The same values of all parameters are used to compare the performance of the proposed control. The values of NARLs and NSD of the three control charts when $n_{N} \epsilon[3,5]$ and $n_{N} \epsilon[8,10]$ are shown in Table 7.

From Table 7, it is clear that the proposed control chart provides smaller values of NARLs compared to [33,39] control charts. For example, when $c=1.05$ and $n_{N} \epsilon(8,10)$, the values of ARL and SD from [39] control chart are 109 and 106, respectively. The values of NARL and NSD from [33] control chart are from 107 to 109 and 102 to 104, respectively. The values of NARL and NSD for the proposed control are from 92 to 100 and 91 to 102, respectively. From this study, it can be seen that the control chart proposed by [39] detects the shift in the process at the 106th sample. The control chart proposed by [33] detects the shift from the 92nd sample and 104th sample. It is quite clear that the proposed chart detects the shift in the process quicker than the existing control charts. From this study, it can be concluded that the use of the proposed control chart may reduce road injuries and road accidents. The proposed chart has the ability to point out the cause of variations for road injuries and road accidents as early as possible.

\section{Road Accidents and Injuries Monitoring Using Simulated Data}

In this section, the performance of the proposed chart for monitoring road accidents and injuries is discussed using the simulated data. The simulated data is generated from the neutrosophic normal distribution. It is assumed that the process is in-control at neutrosophic variance $S_{N 0}^{2} \in[1,1]$. The first 20 values are generated at $S_{N 0}^{2} \in[1,1]$ and the next 20 values are generated from the shifted process when $c=1.25, n_{N} \in[3,5]$ and $\lambda_{N} \in[0.08,0.12]$. The values of the neutrosophic statistic $Z_{k N} \in\left[Z_{k L}, Z_{k U}\right]$ are calculated for the proposed chart, [39] chart and [33] chart and are plotted on control charts in Figures 1-3. Figure 1 shows the proposed control chart, Figure 2 shows the control chart by [33], and Figure 3 depicts [39] control chart. At the specified parameters, the proposed chart should detect the shift in the process from the 9th sample to the 15th sample. From Figure 1, it is clear that the proposed chart detects the shift from the 9th sample to the 
15th sample as expected. In addition, several points are within indeterminacy intervals. The existing chart proposed by [33] detects a shift at the 36th sample. The control chart proposed by [39] does not detect any shift in the process. The simulation study showed that the proposed control chart detected a shift in road accidents and injuries earlier than the existing charts. The use of the proposed control chart will be helpful in minimizing the number of road accidents and injuries.

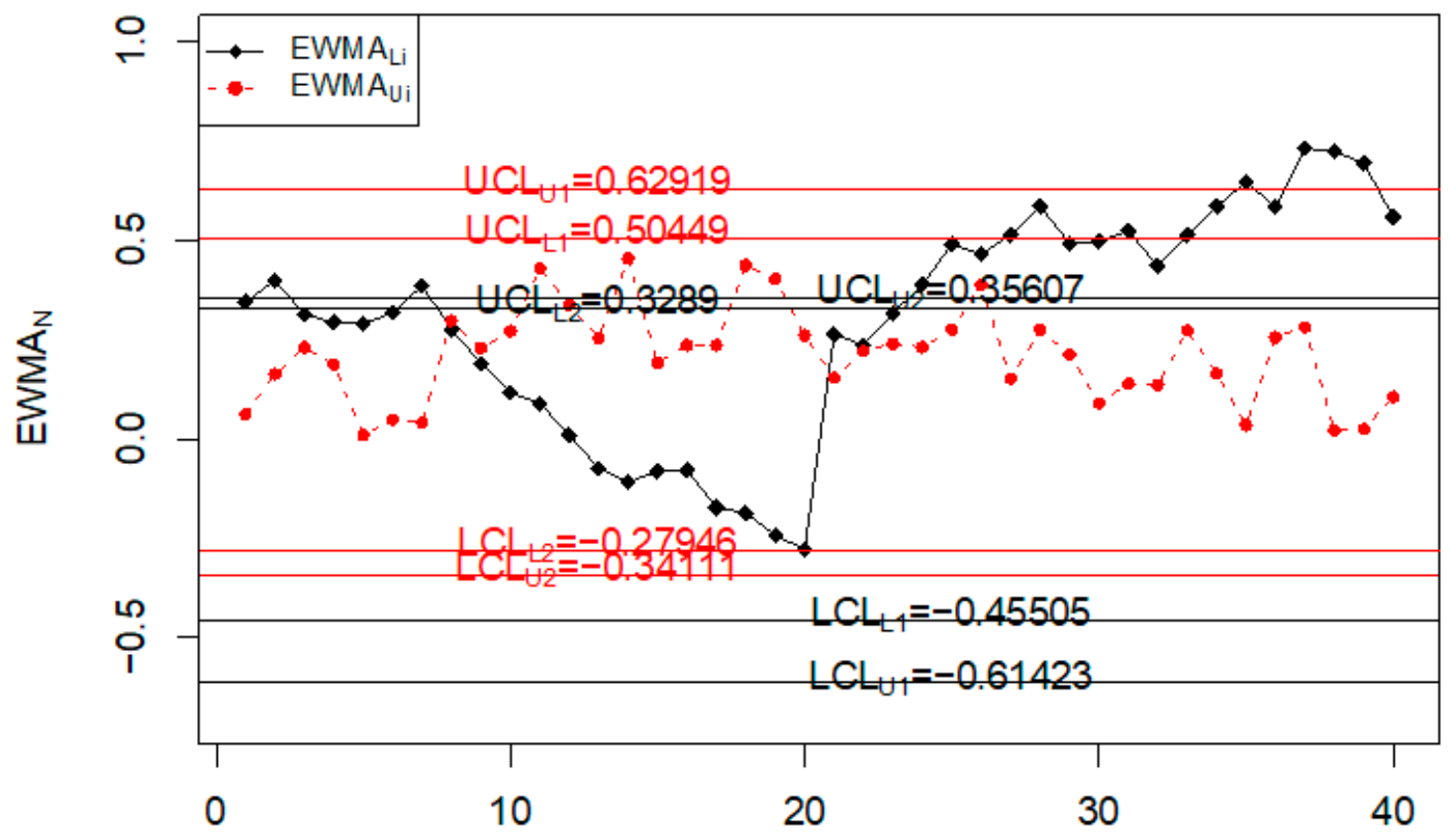

Sample Number

Figure 1. Proposed control chart for simulated data set.

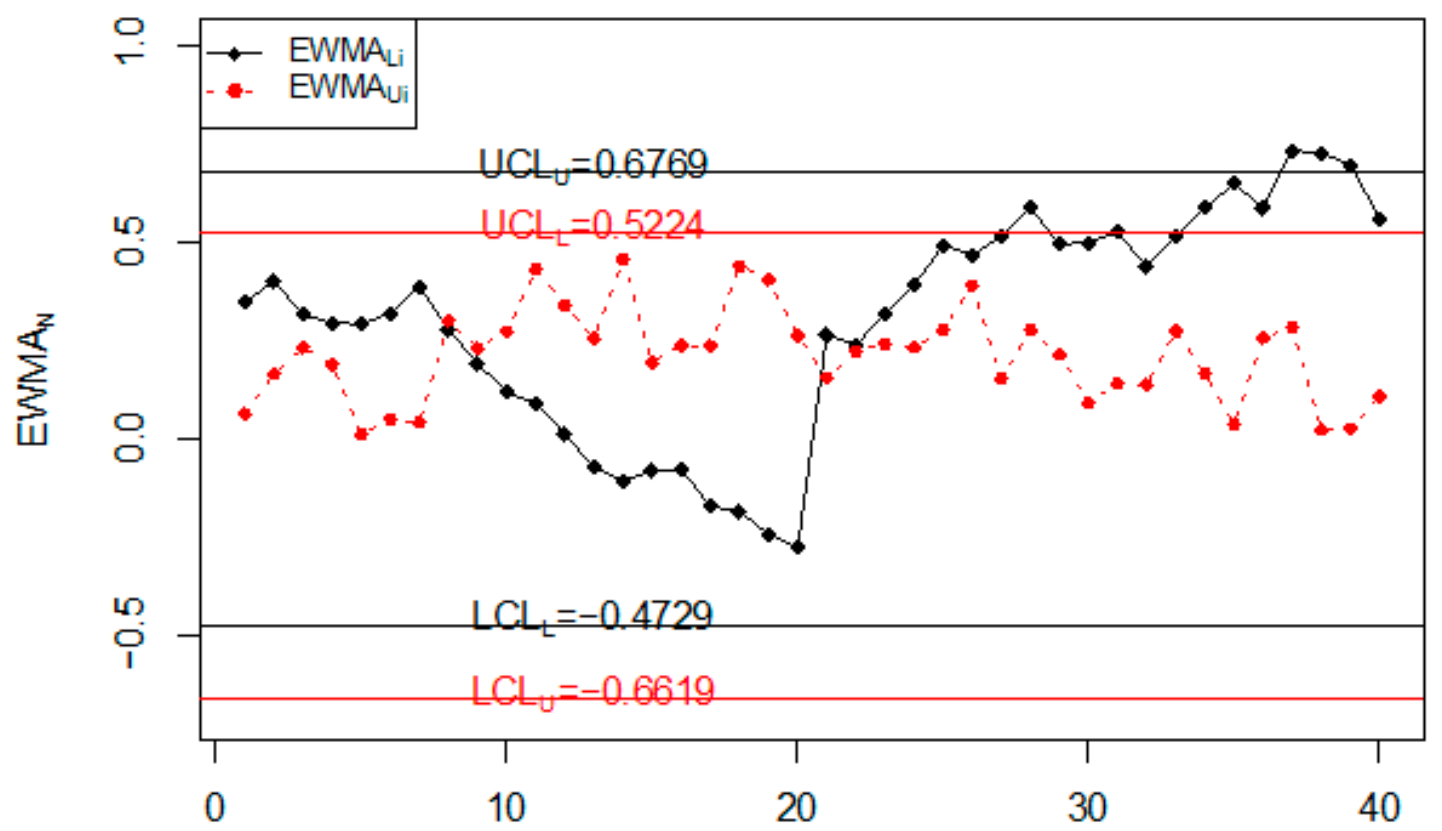

\section{Sample Number}

Figure 2. The control chart by [33] for simulated data set. 
Table 7. The NARL values for the proposed chart and existing chart when $I_{\lambda U}=0.3$.

\begin{tabular}{|c|c|c|c|c|c|c|c|c|c|c|c|c|}
\hline \multirow{3}{*}{ c } & \multirow{2}{*}{\multicolumn{2}{|c|}{$\begin{array}{c}\text { [2] Control Chart } \\
3 \\
\end{array}$}} & \multirow{2}{*}{\multicolumn{2}{|c|}{$\begin{array}{c}\text { [2] Control Chart } \\
8\end{array}$}} & \multirow{2}{*}{\multicolumn{2}{|c|}{$\begin{array}{c}\text { [1] Control Chart } \\
{[3,5]}\end{array}$}} & \multirow{2}{*}{\multicolumn{2}{|c|}{$\begin{array}{c}\text { [1] Control Chart } \\
{[8,10]} \\
\end{array}$}} & \multirow{2}{*}{\multicolumn{2}{|c|}{$\begin{array}{c}\text { Proposed Chart } \\
{[3,5]} \\
\end{array}$}} & \multirow{2}{*}{\multicolumn{2}{|c|}{$\begin{array}{c}\text { Proposed Chart } \\
{[8,10]}\end{array}$}} \\
\hline & & & & & & & & & & & & \\
\hline & ARL & SD & ARL & SD & NARL & NSD & NARL & NSD & NARL & NSD & NARL & NSD \\
\hline 1.05 & 175.73 & 189.55 & 109.31 & 106.95 & {$[175.89,155.28]$} & {$[184.21,153.18]$} & {$[109.14,107.67]$} & {$[104.73,102.66]$} & {$[158.75,135.45]$} & {$[168.84,142.24]$} & {$[100.77,92.29]$} & {$[102.60,91.54]$} \\
\hline 1.1 & 82.72 & 86.61 & 38.47 & 33.1 & {$[81.69,62.06]$} & {$[84.91,58.71]$} & {$[38.37,35.39]$} & {$[32.73,29.6]$} & {$[77.63,51.89]$} & [89.02,52.37] & {$[27.70,24.97]$} & {$[27.70,24.51]$} \\
\hline 1.15 & 45.71 & 46.17 & 20.48 & 14.76 & {$[45.63,33.13]$} & {$[46.57,29.59]$} & {$[20.62,18.75]$} & {$[15.19,13.51]$} & {$[36.97,24.85]$} & {$[40.83,24.06]$} & {$[12.00,10.25]$} & {$[11.50,9.08]$} \\
\hline 1.2 & 29.81 & 28.95 & 13.65 & 8.7 & {$[29.69,21.13]$} & {$[28.94,16.94]$} & {$[13.68,12.32]$} & {$[8.67,7.63]$} & {$[22.66,12.96]$} & {$[25.26,12.71]$} & {$[6.86,5.61]$} & {$[5.81,4.30]$} \\
\hline 1.25 & 21.01 & 18.95 & 10.27 & 5.87 & {$[20.88,15.26]$} & {$[19.43,11.16]$} & {$[10.38,9.3]$} & {$[5.76,4.91]$} & {$[15.05,9.36]$} & {$[17.21,8.72]$} & {$[4.77,3.90]$} & {$[3.94,2.86]$} \\
\hline 1.3 & 16.15 & 13.68 & 8.38 & 4.14 & {$[16.2,11.84]$} & {$[14.1,7.95]$} & {$[8.5,7.5]$} & {$[4.3,3.52]$} & {$[10.88,6.06]$} & {$[12.18,5.59]$} & {$[3.78,2.97]$} & {$[2.78,2.09]$} \\
\hline 1.4 & 11.07 & 8.56 & 6.27 & 2.6 & {$[11.07,8.29]$} & {$[8.49,4.83]$} & {$[6.3,5.63]$} & {$[2.63,2.2]$} & {$[6.75,4.07]$} & {$[6.94,3.47]$} & {$[2.49,2.10]$} & {$[1.66,1.31]$} \\
\hline 1.5 & 8.52 & 5.89 & 5.17 & 1.88 & {$[8.49,6.56]$} & {$[5.92,3.37]$} & {$[5.16,4.65]$} & {$[1.87,1.58]$} & {$[4.46,2.99]$} & {$[4.20,2.29]$} & {$[2.00,1.70]$} & {$[1.23,0.89]$} \\
\hline 1.6 & 7.01 & 4.45 & 4.51 & 1.46 & {$[6.96,5.49]$} & {$[4.42,2.49]$} & {$[4.49,4.05]$} & {$[1.45,1.21]$} & {$[3.66,2.36]$} & {$[3.20,1.60]$} & {$[1.71,1.48]$} & {$[0.92,0.72]$} \\
\hline 1.7 & 6 & 3.48 & 4.02 & 1.18 & {$[5.98,4.78]$} & {$[3.51,1.97]$} & {$[4.02,3.68]$} & {$[1.19,0.99]$} & {$[2.91,2.05]$} & {$[2.42,1.28]$} & {$[1.51,1.35]$} & {$[0.79,0.62]$} \\
\hline 1.8 & 5.32 & 2.87 & 3.72 & 1.03 & {$[5.37,4.33]$} & {$[2.95,1.65]$} & {$[3.7,3.38]$} & {$[1,0.85]$} & {$[2.56,1.75]$} & {$[2.15,1.05]$} & {$[1.39,1.26]$} & {$[0.65,0.54]$} \\
\hline 1.9 & 4.87 & 2.52 & 3.47 & 0.88 & {$[4.87,4]$} & {$[2.57,1.44]$} & {$[3.47,3.15]$} & {$[0.89,0.74]$} & {$[2.21,1.63]$} & {$[1.82,0.92]$} & {$[1.33,1.17]$} & {$[0.58,0.42]$} \\
\hline 2.0 & 4.49 & 2.19 & 3.26 & 0.79 & {$[4.43,3.74]$} & {$[2.14,1.26]$} & {$[3.28,2.99]$} & {$[0.79,0.67]$} & {$[1.88,1.54]$} & {$[1.34,0.81]$} & {$[1.20,1.12]$} & {$[0.45,0.35]$} \\
\hline 2.25 & 3.8 & 1.66 & 2.93 & 0.67 & {$[3.85,3.27]$} & {$[1.7,1.01]$} & {$[2.93,2.67]$} & {$[0.67,0.59]$} & {$[1.67,1.33]$} & {$[1.06,0.60]$} & {$[1.13,1.07]$} & {$[0.37,0.27]$} \\
\hline 2.5 & 3.47 & 1.39 & 2.7 & 0.6 & {$[3.44,2.97]$} & {$[1.37,0.84]$} & {$[2.7,2.47]$} & {$[0.6,0.55]$} & {$[1.54,1.22]$} & {$[1.03,0.49]$} & {$[1.07,1.03]$} & {$[0.27,0.20]$} \\
\hline 3.0 & 2.98 & 1.08 & 2.38 & 0.52 & {$[2.97,2.59]$} & {$[1.05,0.67]$} & {$[2.38,2.2]$} & {$[0.51,0.41]$} & {$[1.30,1.13]$} & {$[0.67,0.38]$} & {$[1.02,1.01]$} & {$[0.15,0.09]$} \\
\hline 4.0 & 2.53 & 0.76 & 2.11 & 0.32 & {$[2.54,2.27]$} & {$[0.75,0.48]$} & {$[2.11,2.04]$} & {$[0.32,0.19]$} & {$[1.15,1.03]$} & {$[0.43,0.18]$} & {$[1.00,1.00]$} & {$[0.07,0.00]$} \\
\hline
\end{tabular}




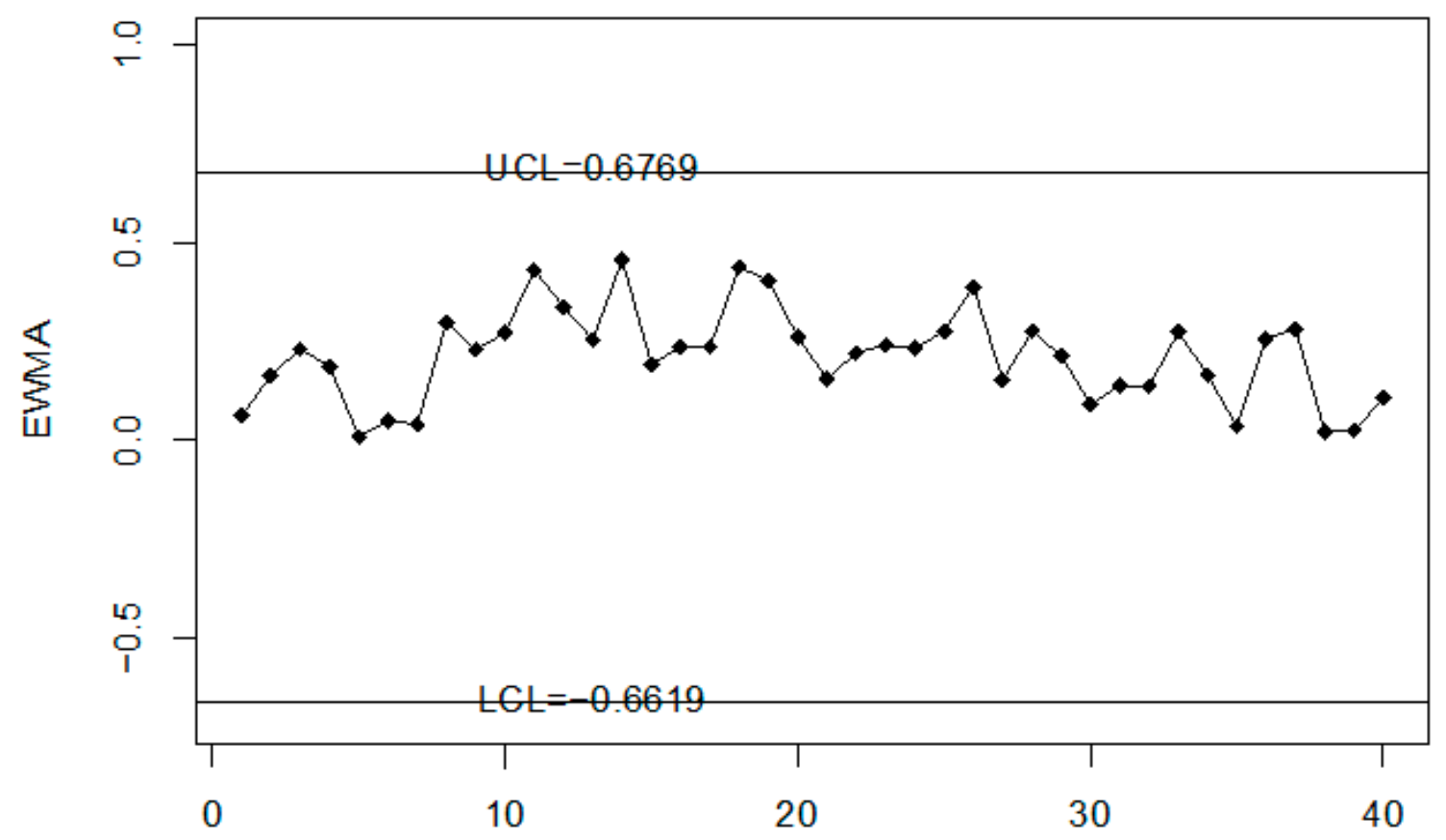

Figure 3. The control chart by [39] for simulated data set.

\section{Road Accidents and Injuries Monitoring Using Real Data}

In this section, the application of the proposed control chart is given with the help of two real examples. The real data of injuries and accidents in Saudi Arabia were collected from https:/ / data.gov.sa/Data/en/dataset/1439/resource/e6a973aa-32a8-4fa2-964c-78 bcf0e8bf58 (accessed on 16 October 2020). The monitoring of road injuries using the proposed control chart and existing charts by $[33,39]$ is discussed in example 1 . Example 2 shows the control chart for monitoring the number of accidents using the proposed control chart and the existing control charts proposed by $[33,39]$.

\subsection{Example 1: Monitoring the Injuries}

For the real-life application of the proposed chart, the injury data of various age ranges of people in different months of the year are reported in Table 8. The injury of people in various months of the year is a variable of interest here. The data are shown in Table 8 . The calculations of the statistic of $T_{k N} \in\left[T_{k L}, T_{k U}\right], Z_{k N} \in\left[Z_{k L}, Z_{k U}\right]$ when $n_{N} \in[5,5]$ and $\lambda_{N} \in[0.08,0.12]$ are also shown in Table 8.

Table 8. Real data related to Injury Data of Jeddah.

\begin{tabular}{ccccccccc}
\hline & \multicolumn{3}{c}{ Age } & & $S_{\boldsymbol{N}}^{2}$ & $\boldsymbol{T}_{\boldsymbol{k N}}$ & NEWMA \\
\hline Months & Less than $\mathbf{1 8}$ & $\mathbf{1 8}$ to $\mathbf{3 0}$ & $\mathbf{3 0}$ to $\mathbf{4 0}$ & $\mathbf{4 0}$ to $\mathbf{5 0}$ & More than $\mathbf{5 0}$ & & $\mathbf{\lambda}=[\mathbf{0 . 0 8 , \mathbf { 0 . 1 2 } ]}$ \\
\hline January & 14 & 59 & 62 & 49 & 27 & 436.7 & 13.482 & $14.4066,14.3664$ \\
February & 11 & 61 & 54 & 39 & 41 & 368.2 & 13.079 & $14.3004,14.2119$ \\
March & 21 & 92 & 71 & 41 & 48 & 756.3 & 14.779 & $14.3387,14.2799$ \\
April & 16 & 79 & 61 & 36 & 36 & 575.3 & 14.1329 & $14.3223,14.2623$ \\
May & 12 & 74 & 61 & 29 & 23 & 697.7 & 14.5886 & $14.3435,14.3015$ \\
June & 18 & 86 & 75 & 33 & 29 & 914.7 & 15.2285 & $14.4143,14.4128$ \\
July & 15 & 76 & 61 & 29 & 38 & 603.7 & 14.2468 & $14.40091,14.3928$ \\
August & 22 & 89 & 88 & 55 & 44 & 837.3 & 15.0196 & $14.4504,14.4680$ \\
September & 25 & 103 & 92 & 62 & 55 & 963.3 & 15.3509 & $14.5225,14.5739$ \\
October & 15 & 89 & 74 & 48 & 34 & 890.5 & 15.1652 & $14.5738,14.6449$ \\
November & 17 & 74 & 55 & 54 & 39 & 450.7 & 13.5564 & $14.4925,14.5143$ \\
December & 15 & 96 & 61 & 44 & 38 & 909.7 & 15.2156 & $14.5503,14.5984$ \\
\hline
\end{tabular}


The Injury level with the different age range in the whole year is shown in Figure 4. So, it can be seen that most people that are injured during road accidents are aged from 18 years to 30 years; less injury is recorded in people whose age is less than 18 years or more than 50 years. The application of the proposed control chart and the two existing charts is also shown using the control chart figures. The monitoring of road injuries using the proposed control chart is shown in Figure 5. The control chart proposed by [33] for the injuries data is shown in Figure 6. Figure 7 presents the control chart proposed by [39]. From Figure 6, it can be noted that some points are in indeterminate intervals and several points are near control limits which are indicating that there may be a shift in the injuries. On the other hand, Figures 6 and 7 show that the number of injuries is within control, and these charts are not indicating any issue in the process. By comparing Figure 5 of the proposed chart with Figures 6 and 7 of the existing control charts, it can be concluded that the proposed chart shows that the decision-makers can expect a shift in road injuries. Therefore, they should be alert and identify the factors for this shift in the process.

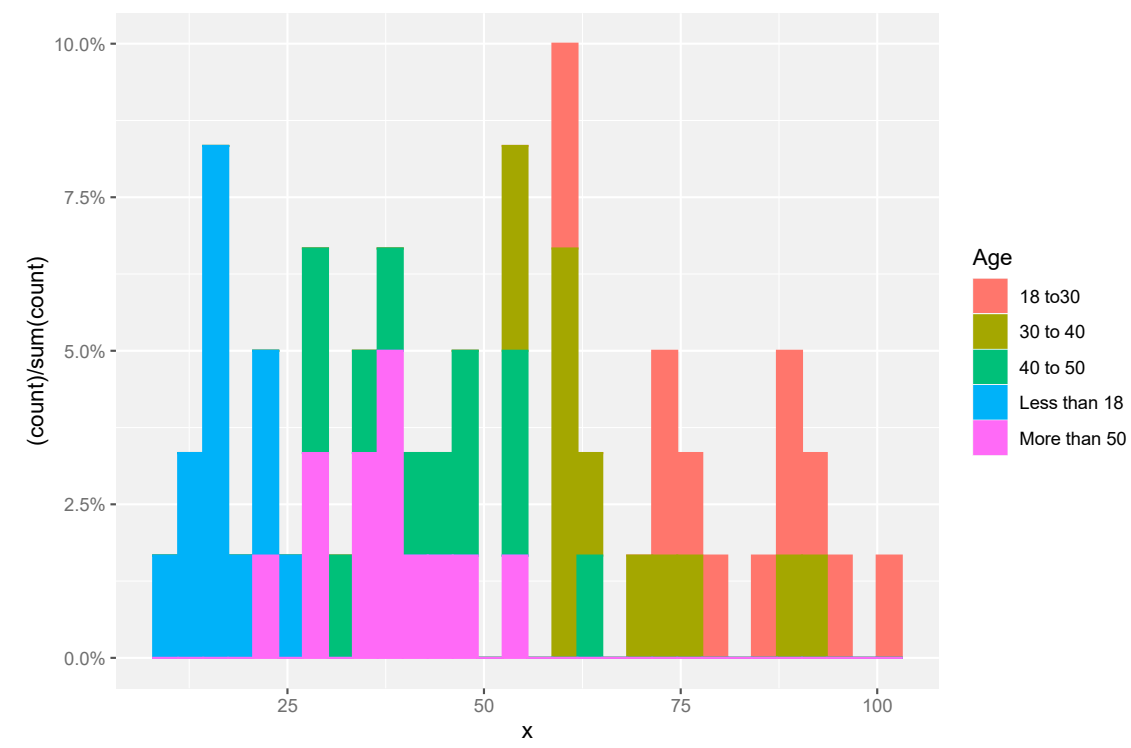

Figure 4. A histogram represents the road accident Injury level with different age group.

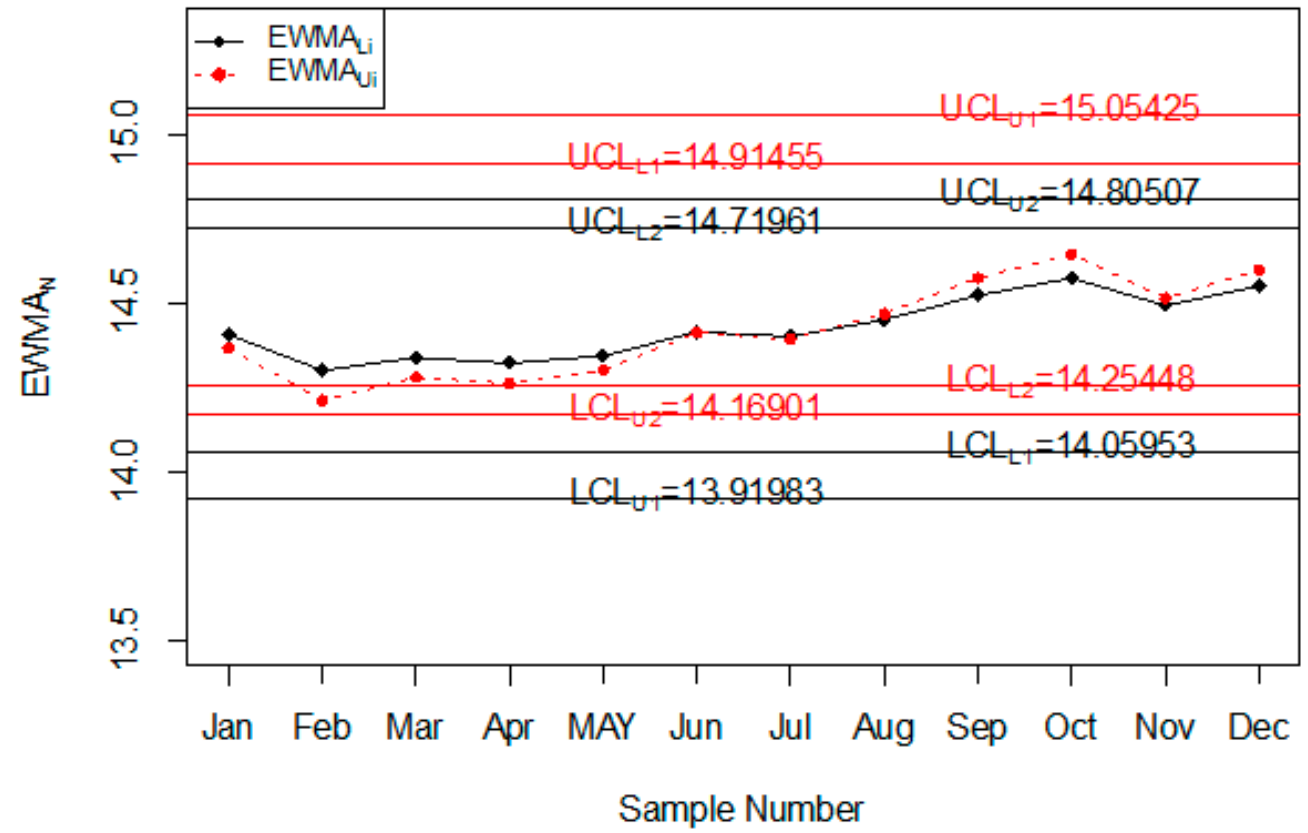

Figure 5. The Proposed control chart for injuries data. 


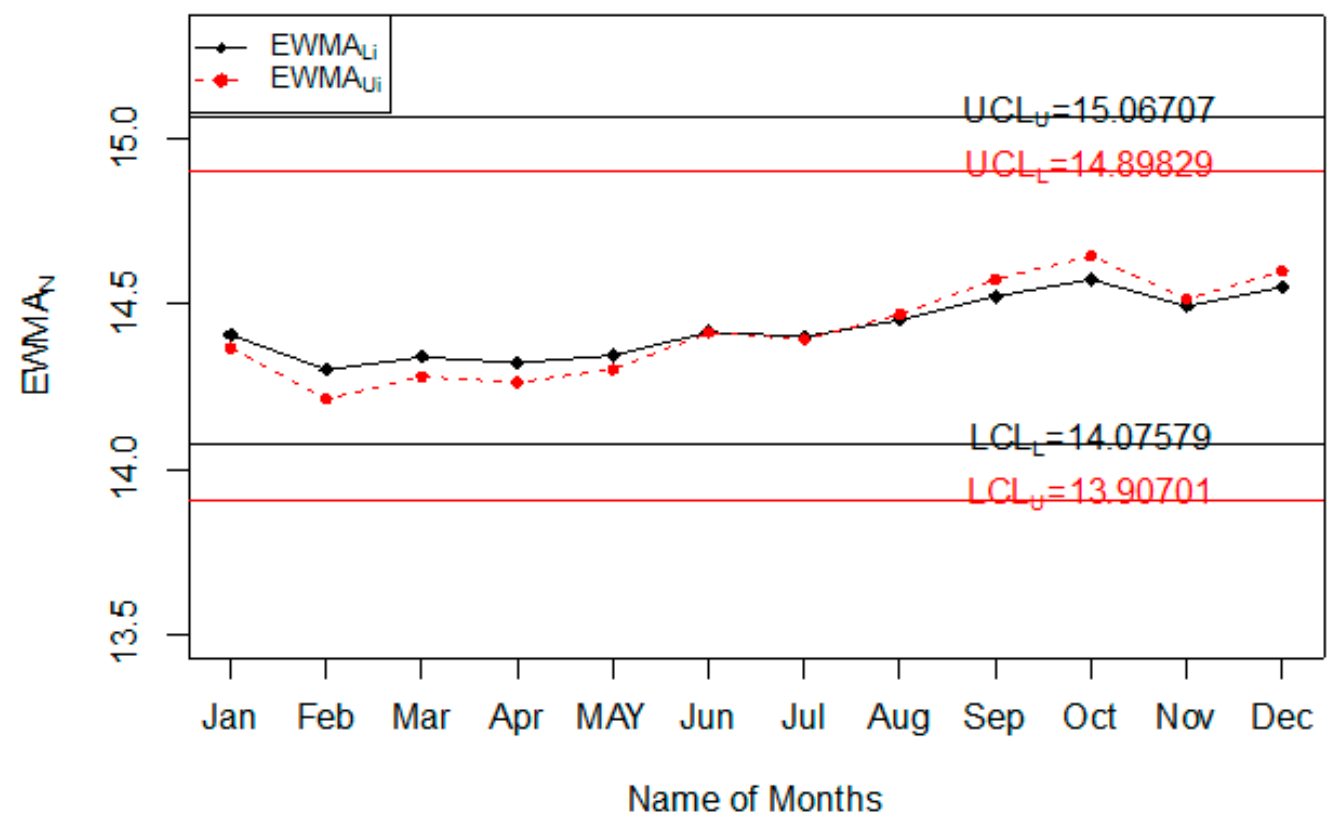

Figure 6. Chart for injuries data.

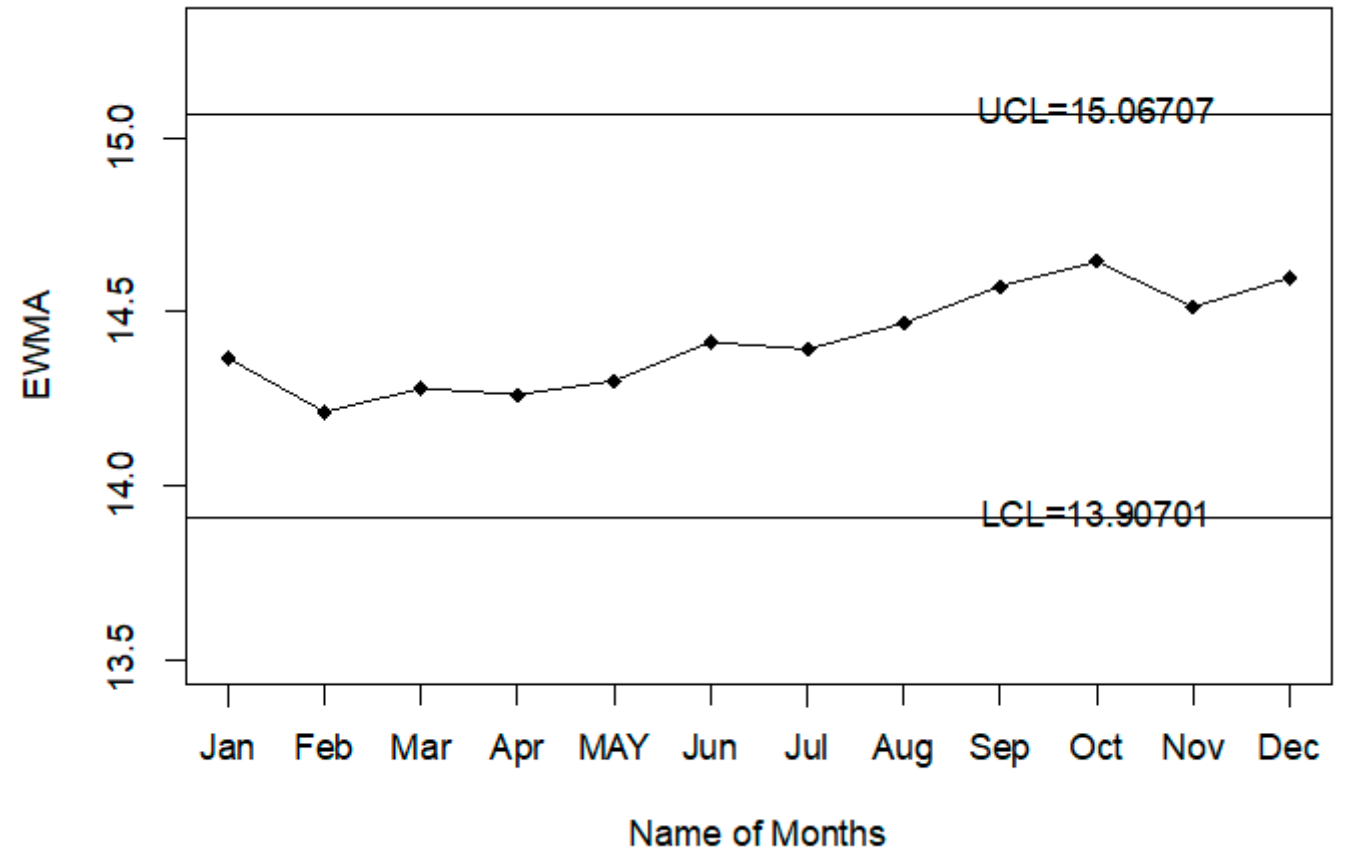

Figure 7. Chart for injuries data.

\subsection{Example 2: Monitoring Road Accidents}

For the application of the proposed chart, the road accident data of all days and weeks of the year are used. The purpose of this example is to monitor road accidents on various days of the week. The data of road accidents are shown in Table 9. The values of the statistic of $T_{k N} \in\left[T_{k L}, T_{k U}\right], Z_{k N} \in\left[Z_{k L}, Z_{k U}\right]$ when $n_{N} \in[5,5]$ and $\lambda_{N} \in[0.08,0.12]$ are also reported in Table 9. The application of the proposed control chart and two existing charts are also shown using the control chart Figures. The monitoring of road accidents using the proposed control chart is shown in Figure 8. The control chart proposed by [33] for road accidents data is shown in Figure 9. Figure 10 presents the control chart for road accidents proposed by [39]. From Figure 8, it can be noted that some points are in indeterminate intervals and several points are near control limits which are indicating that there may be a shift in road accidents. On the other hand, Figures 9 and 10 show that the number of 
road accidents is within control, and these charts are not indicating any issue in the process. By comparing Figure 8 of the proposed chart with Figures 9 and 10 of the existing control charts, it can be concluded that the proposed chart shows that the decision-makers can expect a shift in road accidents. Therefore, they should be alert and identify the factors that cause the shift in road accidents.

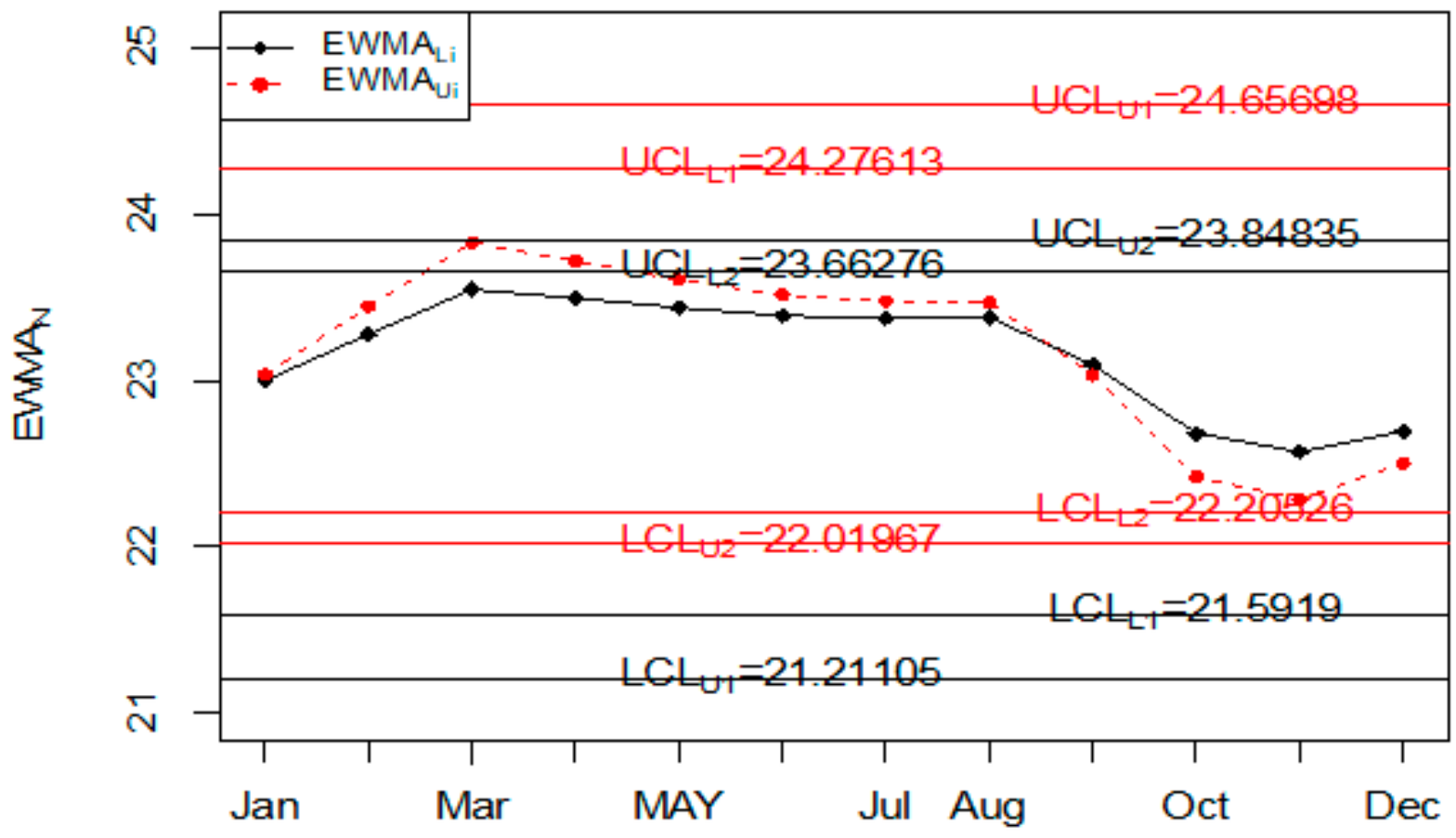

Name of Months

Figure 8. The proposed control chart for accidents data.

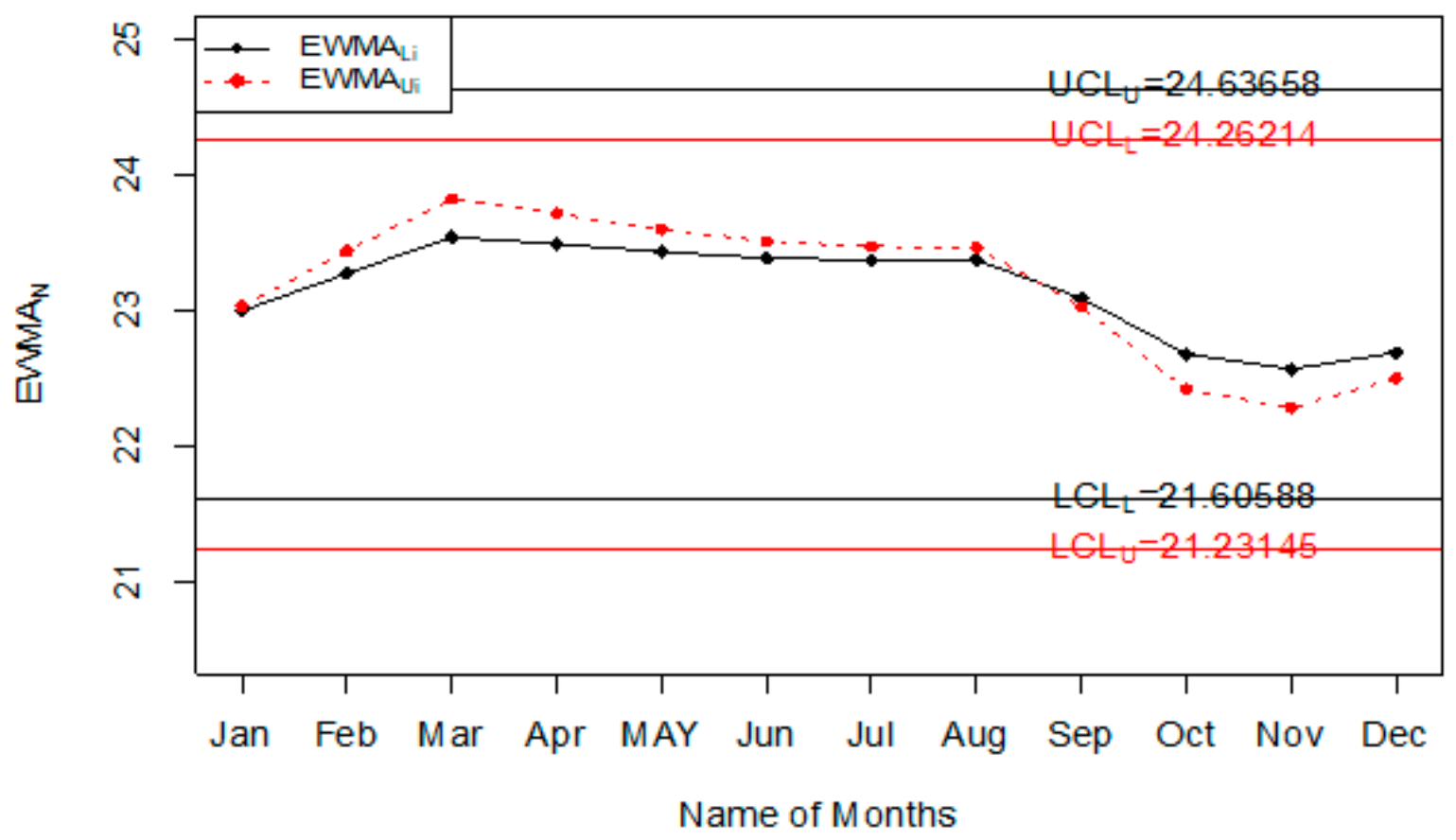

Figure 9. Chart for accidents data [33]. 
Table 9. Accident Data in Jeddah.

\begin{tabular}{|c|c|c|c|c|c|c|c|c|c|c|}
\hline Months & Saturday & Sunday & Monday & Tuesday & Wednesday & Thursday & Friday & $S_{N}^{2}$ & $T_{k N}$ & $\operatorname{NEWMA}[\lambda=[0.08,0.12]]$ \\
\hline January & 426 & 601 & 596 & 586 & 574 & 583 & 407 & 7109.333 & 23.78843 & {$[23.0023659,23.0365426]$} \\
\hline February & 487 & 812 & 525 & 476 & 421 & 498 & 413 & $18,339.81$ & 26.44574 & {$[23.2778358,23.4456463]$} \\
\hline March & 406 & 789 & 551 & 427 & 412 & 498 & 398 & $19,731.24$ & 26.6508 & {$[23.547673,23.8302647]$} \\
\hline April & 448 & 614 & 458 & 407 & 491 & 486 & 407 & 5203.619 & 22.91345 & {$[23.4969351,23.720247]$} \\
\hline May & 423 & 611 & 518 & 457 & 427 & 482 & 412 & 4948.571 & 22.77254 & {$[23.4389835,23.6065221]$} \\
\hline June & 530 & 590 & 563 & 475 & 479 & 511 & 372 & 5080.476 & 22.8463 & {$[23.3915688,23.5152955]$} \\
\hline July & 493 & 623 & 511 & 587 & 587 & 528 & 396 & 5800.81 & 23.21808 & {$[23.3776897,23.4796296]$} \\
\hline August & 453 & 652 & 579 & 578 & 552 & 503 & 427 & 6195.81 & 23.40279 & {$[23.3796977,23.4704089]$} \\
\hline October & 378 & 412 & 422 & 413 & 382 & 456 & 373 & 880.8095 & 17.93394 & {$[22.6834248,22.4225315]$} \\
\hline November & 394 & 533 & 449 & 380 & 393 & 405 & 394 & 2917.81 & 21.2914 & {$[22.5720629,22.2867958]$} \\
\hline December & 402 & 576 & 517 & 397 & 388 & 419 & 307 & 7961.619 & 24.10591 & {$[22.6947706,22.5050895]$} \\
\hline
\end{tabular}




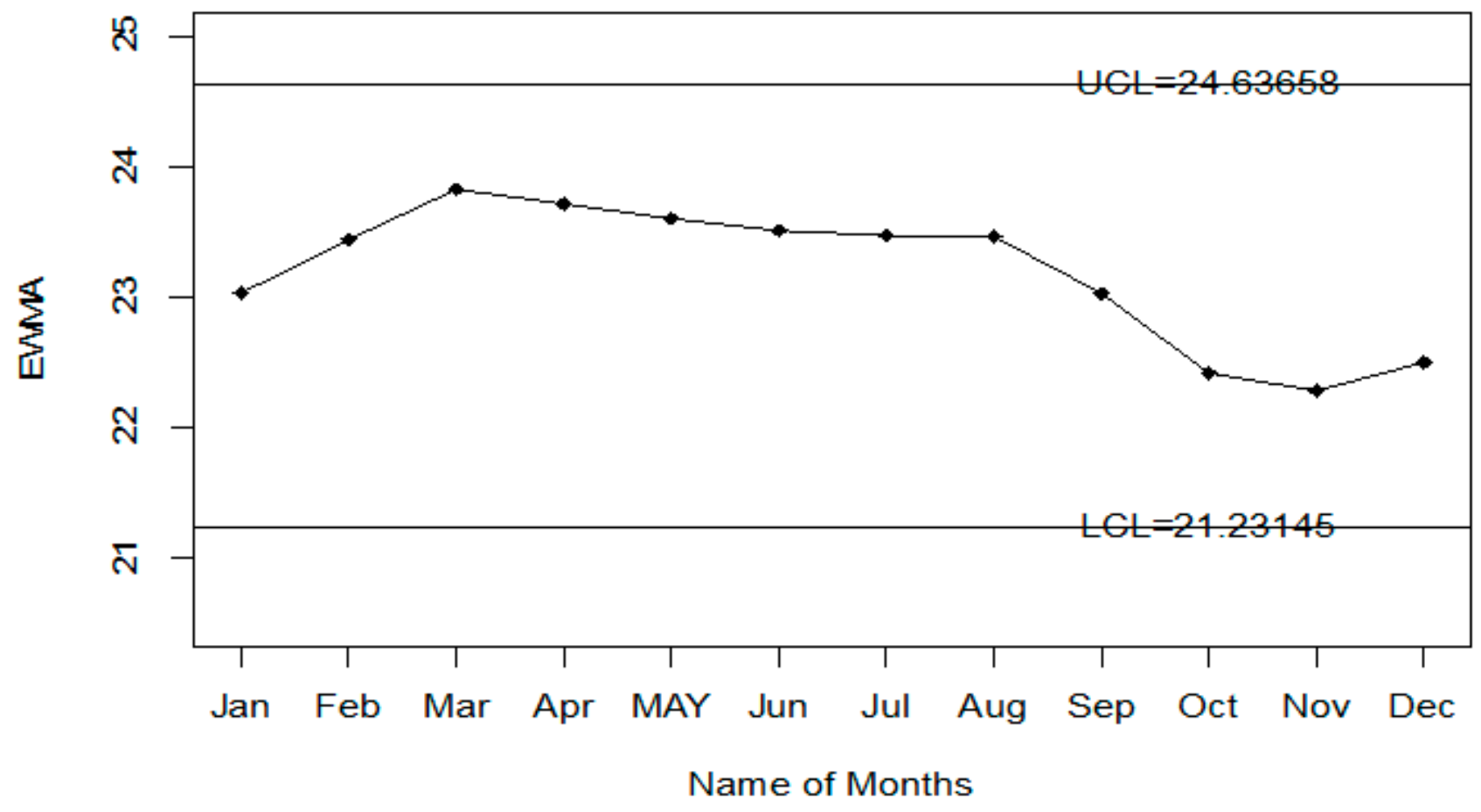

Figure 10. Chart for accidents data set.

\section{Concluding Remarks}

The $S_{N}^{2}-N E W M A$ control chart for monitoring road accidents and road injuries when the smoothing constant is uncertain was presented in the paper. The operational procedure of the proposed chart was explained. The neutrosophic Monte Carlo simulation for the proposed control chart was introduced and used to present the Tables and control chart Figures. The comparative study showed that the proposed control chart is quite an effective tool in monitoring road accidents and road injuries. The efficiency of the proposed control chart was shown over two control charts in terms of NARL. Based on the analysis, it is recommended to apply the proposed control chart in monitoring highways and motorways to minimize road accidents and injuries. The proposed control chart using a cost model can be studied as future research. The proposed control chart using the rank set sampling scheme is also a fruitful area for future research. The seasonal trend of the series of accidents and injuries can be studied as future research.

Author Contributions: Conceptualization, M.A. (Muhammad Asalam) and M.A. (Mohammed Albassam); methodology, M.A. (Mohammed Albassam); software, M.A. (Muhammad Asalam); validation, M.A. (Muhammad Asalam) and M.A. (Mohammed Albassam). All authors have read and agreed to the published version of the manuscript.

Funding: This article was funded by the Deanship of Scientific Research (DSR) at King Abdulaziz University, Jeddah. The author therefore acknowledges DSR with thanks for technical and financial support.

Institutional Review Board Statement: Not applicable.

Informed Consent Statement: Not applicable.

Data Availability Statement: The data are given in the paper.

Conflicts of Interest: The authors declare no conflict of interest. 


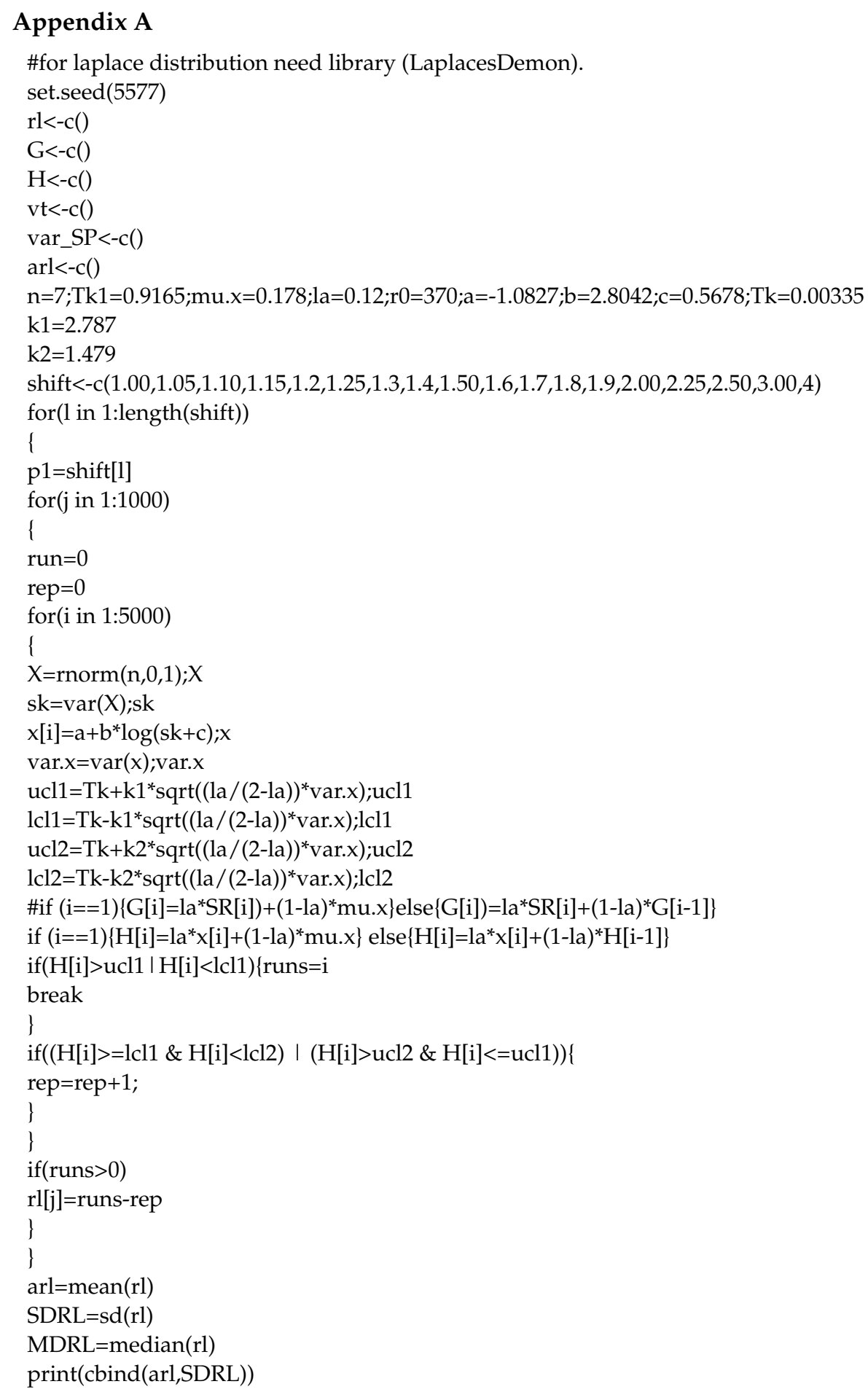

\section{References}

1. Irianto, D.; Juliani, A. A two control limits double sampling control chart by optimizing producer and customer risks. J. Eng. Technol. Sci. 2010, 42, 165-178. [CrossRef]

2. Abbas, N.; Saeed, U.; Riaz, M.; Abbasi, S.A. On designing an assorted control charting approach to monitor process dispersion: An application to hard-bake process. J. Taibah Univ. Sci. 2019, 14, 65-76. [CrossRef]

3. Pokropp, F.; Seidel, W.; Begun, A.; Heidenreich, M.; Sever, K. Control Charts for the Number of Children Injured in Traffic Accidents Frontiers in Statistical Quality Control 8; Springer: Berlin/Heidelberg, Germany, 2006; pp. 151-171.

4. Rębisz, B. The study of the dynamics of traffic accidents using the control charts. Mod. Manag. Rev. 2013, 18, 135-144. [CrossRef]

5. Schuh, A.; Camelio, J.A.; Woodall, W.H. Control charts for accident frequency: A motivation for real-time occupational safety monitoring. Int. J. Inj. Control. Saf. Promot. 2013, 21, 154-162. [CrossRef] [PubMed] 
6. Baradaran, V.; Dashtbani, H. A decision support system for monitoring traffic by statistical control charts. Manag. Sci. Lett. 2014, 4, 1661-1670. [CrossRef]

7. Mannering, F.L.; Shankar, V.; Bhat, C.R. Unobserved heterogeneity and the statistical analysis of highway accident data. Anal. Methods Accid. Res. 2016, 11, 1-16. [CrossRef]

8. Olanrewaju, F.; Daniel, O.O.; Tajudeen, A.A. Comparative Analysis on EWMA and Poisson Cusum Chart in the Assessment of Road Traffic Crashes (RTC) in Osun State Nigeria. Am. J. Theor. Appl. Stat. 2017, 6, 95. [CrossRef]

9. Alogaili, A.; Mannering, F. Unobserved heterogeneity and the effects of driver nationality on crash injury severities in Saudi Arabia. Accid. Anal. Prev. 2020, 144, 105618. [CrossRef]

10. Li, Q.; Li, X.; Mannering, F. A Statistical Study of Discretionary Lane-changing Decision with Heterogeneous Vehicle and Driver Characteristics. Transp. Res. Rec. 2020. [CrossRef]

11. Stokes, R.W.; Mutabazi, M.I. Rate-quality control method of identifying hazardous road locations. Transp. Res. Rec. 1996, 1542, 44-48. [CrossRef]

12. Mansuri, F.A.; Al-Zalabani, A.H.; Zalat, M.M.; Qabshawi, R.I. Road safety and road traffic accidents in Saudi Arabia: A systematic review of existing evidence. Saudi Med. J. 2015, 36, 418. [CrossRef] [PubMed]

13. Alnawmasi, N.; Mannering, F. A statistical assessment of temporal instability in the factors determining motorcyclist injury severities. Anal. Methods Accid. Res. 2019, 22, 100090. [CrossRef]

14. Tang, J.; Zheng, L.; Han, C.; Yin, W.; Zhang, Y.; Zou, Y.; Huang, H. Statistical and machine-learning methods for clearance time prediction of road incidents: A methodology review. Anal. Methods Accid. Res. 2020, 27, 100123. [CrossRef]

15. Rissanen, R.; Ifver, J.; Hasselberg, M.; Berg, H.-Y. Quality of life following road traffic injury: The impact of age and gender. Qual. Life Res. 2020, 29, 1587-1596. [CrossRef] [PubMed]

16. Islam, M.; Alnawmasi, N.; Mannering, F. Unobserved heterogeneity and temporal instability in the analysis of work-zone crash-injury severities. Anal. Methods Accid. Res. 2020, 28, 100130. [CrossRef]

17. Smarandache, F. Introduction to neutrosophic statistics. Infin. Study 2014. [CrossRef]

18. Smarandache, F.; Khalid, H.E. Neutrosophic precalculus and neutrosophic calculus. Infin. Study 2015. [CrossRef]

19. Aslam, M. Monitoring the road traffic crashes using NEWMA chart and repetitive sampling. Int. J. Inj. Control. Saf. Promot. 2021, 28, 39-45. [CrossRef] [PubMed]

20. Chen, J.; Ye, J.; Du, S. Scale Effect and Anisotropy Analyzed for Neutrosophic Numbers of Rock Joint Roughness Coefficient Based on Neutrosophic Statistics. Symmetry 2017, 9, 208. [CrossRef]

21. Chen, J.; Ye, J.; Du, S.; Yong, R. Expressions of Rock Joint Roughness Coefficient Using Neutrosophic Interval Statistical Numbers. Symmetry 2017, 9, 123. [CrossRef]

22. Aslam, M. A new method to analyze rock joint roughness coefficient based on neutrosophic statistics. Measurement 2019, 146, 65-71. [CrossRef]

23. Kahraman, C.; Bozdag, C.E.; Ruan, D.; Ozok, A.F. Fuzzy sets approaches to statistical parametric and nonparametric tests. Int. J. Intell. Syst. 2004, 19, 1069-1087. [CrossRef]

24. Grzegorzewski, P. k-sample median test for vague data. Int. J. Intell. Syst. 2009, 24, 529-539. [CrossRef]

25. Shafiq, M.; Atif, M.; Viertl, R. Generalized Likelihood Ratio Test and Cox'sF-Test Based on Fuzzy Lifetime Data. Int. J. Intell. Syst. 2016, 32, 3-16. [CrossRef]

26. Du, W.S. Correlation and correlation coefficient of generalized orthopair fuzzy sets. Int. J. Intell. Syst. 2019, 34, 564-583. [CrossRef]

27. Grzegorzewski, P.; Śpiewak, M. The sign test and the signed-rank test for interval-valued data. Int. J. Intell. Syst. 2019, 34, 2122-2150. [CrossRef]

28. Singh, S.; Ganie, A.H. On some correlation coefficients in Pythagorean fuzzy environment with applications. Int. J. Intell. Syst. 2020, 35, 682-717. [CrossRef]

29. Flores, M.; Naya, S.; Fernández-Casal, R.; Zaragoza, S.; Raña, P.; Tarrío-Saavedra, J. Constructing a Control Chart Using Functional Data. Mathematics 2020, 8, 58. [CrossRef]

30. Al-Marshadi, A.H.; Shafqat, A.; Aslam, M.; Alharbey, A. Performance of a New Time-Truncated Control Chart for Weibull Distribution Under Uncertainty. Int. J. Comput. Intell. Syst. 2021, 14, 1256. [CrossRef]

31. Ajadi, J.O.; Wang, Z.; Zwetsloot, I.M. A review of dispersion control charts for multivariate individual observations. Qual. Eng. 2020, 1-16. [CrossRef]

32. Aslam, M.; Al-Marshadi, A.H.; Khan, N. A New X-Bar Control Chart for Using Neutrosophic Exponentially Weighted Moving Average. Mathematics 2019, 7, 957. [CrossRef]

33. Aslam, M.; Bantan, R.A.; Khan, N. Design of S2N-NEWMA Control Chart for Monitoring Process having Indeterminate Production Data. Processes 2019, 7, 742. [CrossRef]

34. Sherman, R.E. Design and evaluation of a repetitive group sampling plan. Technometrics 1965, 7, 11-21. [CrossRef]

35. Box, G.E.; Hunter, W.G.; Hunter, J.S. Statistics for Experimenters; John Wiley and Sons: New York, NY, USA, 1978.

36. Crowder, S.V.; Hamilton, M.D. An EWMA for Monitoring a Process Standard Deviation. J. Qual. Technol. 1992, $24,12-21$. [CrossRef]

37. Bissell, D.; Montgomery, D.C. Introduction to Statistical Quality Control. J. R. Stat. Soc. Ser. D 1986, 35, 81. [CrossRef] 
38. Johnsson, N.; Kotz, S.; Balakrishnan, N. Continuous Univariate Distributions; John Wiley and Sons: New York, NY, USA, 1994; Volume 1.

39. Castagliola, P. A NewS2-EWMA Control Chart for Monitoring the Process Variance. Qual. Reliab. Eng. Int. 2005, 21, 781-794. [CrossRef] 